\title{
Espacios para la investigación y la transferencia: una apuesta de la Universidad de Salamanca en el siglo XXI
}

\author{
Spaces for Research and Transfer, a commitment \\ of the University of Salamanca in the $21^{\text {st }}$ century
}

\author{
Ma Nieves Rupérez Almajano* \\ Universidad de Salamanca \\ ORCID ID: 0000-0002-1894-5198
}

Recibido: $\quad 21 / 05 / 2020$

Aceptado: $\quad 13 / 10 / 2020$

DOI: https://doi.org/10.20318/cian.2020.5797

Resumen: En lo que va de siglo, la adaptación al Espacio Europeo de Educación Superior no solo ha supuesto cambios en la docencia de las universidades, sino también un impulso para la investigación y la transferencia de conocimientos a la sociedad, acompañado de la creación de espacios específicos
Abstract: So far this century, the adaptation to the European Higher Education Area has not only changed university teaching but has also involved a boost for research and knowledge transfer to society. This has been accompanied by the construction of specific spaces for its development. The cen-

\footnotetext{
"nruperez@usal.es.

Este trabajo se ha desarrollado en el marco del proyecto "La Universidad en Castilla y León: Patrimonio y sostenibilidad" (SA029G19), financiado por la Consejería de Educación de la Junta de Castilla y León al GIR Arte y Patrimonio Universitario. Quiero manifestar mi especial agradecimiento a los arquitectos Fernando Sánchez Cuadrado y Pablo Núñez Paz por los materiales facilitados con total generosidad, así como por su disponibilidad para atender a mis consultas. Este reconocimiento es extensivo a Luis Asín y, particularmente, a Vicente Sierra Puparelli, con quienes estoy en deuda por las fotografías que ilustran este trabajo.
} 
para su desarrollo. La centenaria Universidad de Salamanca, tradicionalmente unida a la ciudad, además de conservar e incrementar el patrimonio arquitectónico heredado de épocas pasadas, ha optado por ampliar su área de influencia con nuevos campus en ubicaciones periféricas y ha apostado decididamente por arquitecturas de nuevo cuño, adaptadas plenamente a las nuevas funciones, que han diversificado las tipologías a su servicio. Ejemplo de ello son las sedes de Institutos de Investigación del ámbito de las Biociencias y el campus de Villamayor, donde se ha desarrollado el Parque Científico, que son objeto de nuestra atención en esta ocasión.

Palabras clave: Universidad de Salamanca, arquitectura, tipologías universitarias, campus, investigación, Biociencias. tury-old University of Salamanca, traditionally linked to the city, who has also preserved and increased the architectural heritage inherited from the past, has chosen to expand its area of influence with new campuses in peripheral locations. It has made a firm commitment to a new architecture, fully adapted to the new features, which has increased the different types of buildings that serve the University. Some examples on which we will focus on this occasion are the headquarters of the Research Institutes in the Biosciences field and the campus of Villamayor, where the Science Park was built.

Keywords: University of Salamanca, Architecture, Typology of Universities, Campus, Research, Biosciences.

En lo que va de siglo, varios centros de investigación, facultades y servicios se han ido sumando a las propuestas científicas y educativas ofertadas por la centenaria Universidad de Salamanca. Dejando al margen otros posibles análisis, en este caso nos interesa resaltar las consecuencias que este impulso ha tenido a nivel urbanístico y arquitectónico, especialmente en una ciudad en la que la institución académica ha sido desde su fundación uno de sus principales motores de crecimiento y el origen, junto con los colegios vinculados a ella, de gran parte de su patrimonio artístico.

Hoy, como ayer, también esta Universidad, con el apoyo de los poderes públicos -locales, pero especialmente autonómicos y estatales- se ha convertido en un destacado promotor inmobiliario. Cuenta con una Unidad Técnica, dependiente de un vicerrectorado y dirigida por un arquitecto ${ }^{1}$, que se ocupa del mantenimiento, mejora y adecuación de los más de ochenta edificios de su propiedad distribuidos en distintas localidades (Salamanca, Béjar, Ávila y Zamora fundamentalmente), con una gran diversidad formal, funcional y de superficie, así como cronológica, dado que abarcan más de cinco siglos, desde fines del XV al XXI. Corresponde también a este servicio la redacción de los programas de necesidades funcionales y tecnológicas de los

\footnotetext{
${ }^{1}$ Este vicerrectorado ha variado según los equipos de gobierno: Innovación e Infraestructuras, Economía y Mejora de la Gestión o, en la actualidad, vicerrectorado de Economía. Desde julio de 1996 dirigió la Unidad Técnica el arquitecto Luis Ferreira Villar, hasta mayo de 2008 en que pasó a ser asesor para el patrimonio arquitectónico, ocupando su puesto Eduardo Dorado Díez. BOE, 7/08/1996 y BOCyL, 14/05/2008.
} 
inmuebles de nueva construcción de acuerdo con la disponibilidad económica y de espacio. En algunos casos, desde esta oficina técnica se proyectaron esas nuevas infraestructuras, pero habitualmente su labor se ha centrado en la supervisión del desarrollo y finalización de las obras, cuyos diseños se sacaron a concurso público, habiendo correspondido a este servicio únicamente la confección de los pliegos de prescripciones y la gestión de los contratos.

El sistema de concurso ha favorecido la variedad formal de estos edificios universitarios que obedecen a diversos planteamientos y reflexiones sobre el quehacer arquitectónico, lo que impide englobarlos en un denominador común. Hay, sin embargo, en ellos una apuesta por la incorporación de soluciones innovadoras, de las que en algunos casos han sido pioneros. Son también ejemplos destacados de la arquitectura del siglo XXI y no solo de Salamanca.

Por limitación de espacio, nos centraremos en esta ocasión en las sedes de Institutos de Investigación del ámbito de las Biociencias - una de las apuestas de esta Universidad para obtener el reconocimiento de "Campus de Excelencia Internacional"- ${ }^{2}$, inauguradas en el nuevo siglo y en las construcciones del Campus de Villamayor.

\section{Nuevos espacios para la investigación}

La relación entre docencia e investigación ha sido siempre esencial en la enseñanza universitaria. Durante décadas ambas actividades compartieron unas mismas instalaciones y así sigue ocurriendo, en el caso de la Universidad de Salamanca, con muchos de los institutos universitarios que se han ido constituyendo en las últimas décadas dedicados a la investigación científica, técnica, artística o docente ${ }^{3}$. No obstante, el incremento exponencial de los investigadores en algunas áreas y la exigencia de especiales requisitos tecnológicos han obligado a construir inmuebles con unas condiciones específicas en los que los laboratorios acaparan la mayor parte del espacio ${ }^{4}$. Estos centros tampoco son ajenos por completo a la faceta docente, que llevan a cabo

${ }^{2}$ Proyecto Studii Salamantini: 800 años innovando. Disponible en: http://cei.usal.es/proyecto/ [citado el 4 de mayo 2020].

${ }^{3}$ En la actualidad tiene trece institutos: https://www.usal.es/institutos-investigacion [citado el 29 de abril 2020].

${ }^{4}$ Sobre esta tipología, Brian Edward, University Architecture (London: Spon Press, 2000), 164 y ss. David J. Neuman, Building type basis for college and University Facilities (Hoboken NJ: John Wiley, 2013), 178-218. 
al más alto nivel a través de programas de máster, doctorado y diversos cursos de formación, pero su repercusión arquitectónica es mucho menor que la actividad I+D que desarrollan. Dada la incidencia social de sus trabajos, la Universidad ha recibido apoyo desde distintas instancias para potenciarlos.

Con respecto a su ubicación, la tendencia ha sido emplazarlos en el campus Miguel de Unamuno, al oeste de la ciudad y principal área de expansión de la vida académica desde finales del siglo XX, o en sus proximidades cuando esto no ha sido posible, incrementando la variedad de tipologías -facultades, aularios, bibliotecas, residencias o instalaciones deportivas- levantadas allí ${ }^{5}$.

\section{El Centro de Investigación del Cáncer}

El Centro de Investigación del Cáncer fue el primer edificio en inaugurarse en el nuevo milenio, el 27 de enero de 2000. Con él se hacía realidad la idea gestada años atrás de reunir a destacados investigadores de esta materia que hasta el momento habían estado dispersos en distintos departamentos. Se trata de un instituto mixto, dependiente de la Universidad de Salamanca -que aprobó su creación en 1996- y del CSIC, que desde el principio colaboró en la iniciativa. Está también reconocido como centro sanitario por el Sistema de Salud de Castilla y León (SACYL).

Responde al modelo de los Comprehensive Cancer Center norteamericanos, caracterizados por integrar investigación competitiva y de excelencia sobre el cáncer en los niveles biomédico básico, clínico y aplicado. Tiene así un carácter multidisciplinar y se ha convertido en una referencia indiscutible a nivel nacional e internacional ${ }^{6}$.

Doce arquitectos concurrieron al concurso convocado en 1996 para diseñar el Instituto de Investigación del Cáncer ${ }^{7}$, cuyo proyecto de ejecución redactó finalmente Emilio Sánchez $\mathrm{Gil}^{8}$ junto con el arquitecto de la Unidad

${ }^{5}$ Sara Cañizal Sardón, La Universidad de Salamanca de la posguerra a la actualidad. Patrimonio arquitectónico y trascendencia urbana (Tesis doctoral: Universidad de Salamanca, 2009), 1, 217-269; 2, 690-781. Ma Teresa Paliza y David Senabre, "Arquitecturas y espacios universitarios, siglos XIX y XX", en Historia de la Universidad de Salamanca. II. Estructuras y flujos, coord. Luis Enrique Rodríguez-San Pedro Bezares (Salamanca: Ediciones de la Universidad de Salamanca, 2002), 514-518.

${ }^{6}$ Para los aspectos específicos: http://www.cicancer.org/es [citado el 6 de mayo 2020].

${ }^{7}$ BOCyL, 29/05/1996.

${ }^{8}$ Este arquitecto ha desarrollado una intensa y reconocida actividad, extensiva al campo de la restauración y el urbanismo. A él se deben también, en la Universidad de Salamanca, las Facultades de Geografía e Historia, Enfermería y Fisioterapia y Odontología. 
Técnica Luis Ferreira Villar. Una vez concluido, en septiembre de 1997, fue adjudicado a la empresa Dragados por un presupuesto cercano a los seiscientos millones de pesetas. La primera piedra se puso el 20 de enero de 1998 y el edificio estaba terminado en el verano de $1999^{9}$. La construcción y su posterior equipamiento fue posible gracias a un convenio firmado el 5 de marzo de 1997 entre la Universidad de Salamanca, el CSIC, la Junta de Castilla y León, el Ministerio de Educación, la Diputación Provincial de Salamanca, el Ayuntamiento y Caja Salamanca y Soria.

El diseño propuesto por Sánchez Gil tuvo muy en cuenta la topografía del lugar elegido para su emplazamiento, una parcela de acusada pendiente cercana al Tormes, al sur del campus Unamuno, inmediata a la Facultad de Farmacia y próxima asimismo a las de Farmacia, Biología y al Hospital Clínico, edificios con los que pretende también evitar cualquier competencia.

Plantea una macla de dos cuerpos claramente diferenciados acordes con la dualidad de exigencias funcionale ${ }^{10}$. Por un lado, un volumen rectan-

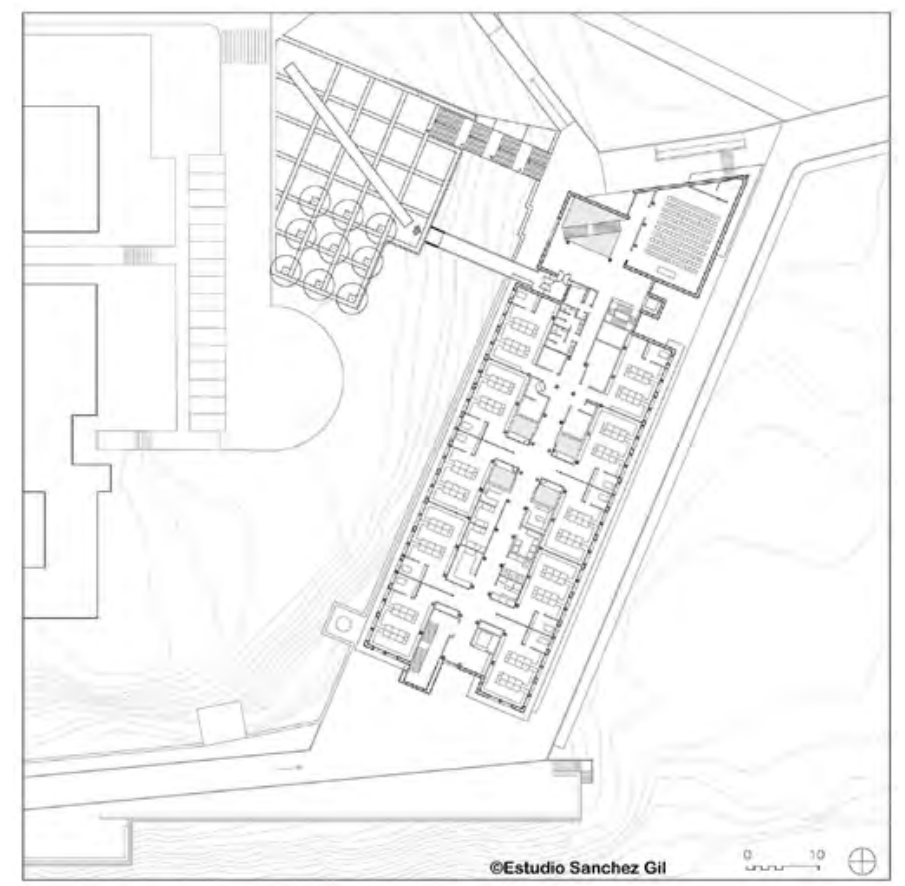

\footnotetext{
${ }^{9}$ Cañizal (2009), 2, 762-769 y 940.

${ }^{10}$ Sobre el edificio, Emilio Sánchez Gil, “Instituto de Investigación del Cáncer. Salamanca”, On Diseño, 227 (2001): 188-199.
} 


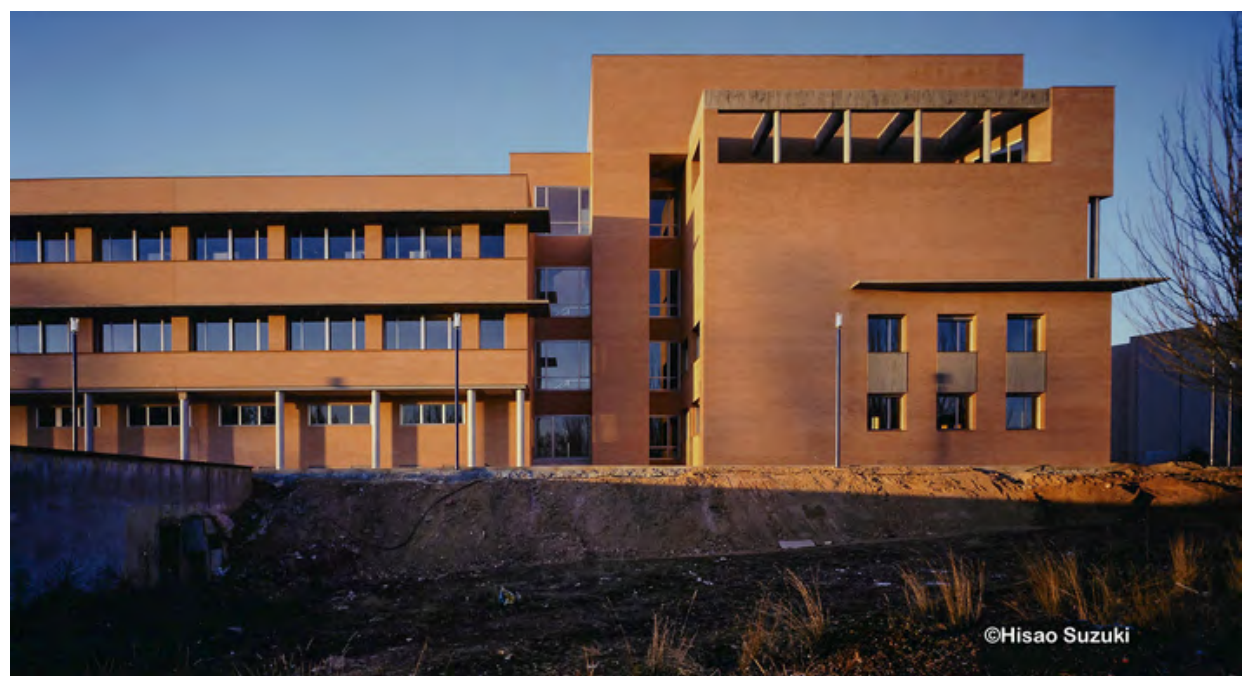

gular de tres plantas de marcado desarrollo longitudinal, perpendicular al máximo desnivel, que acoge los diferentes laboratorios distribuidos a ambos lados de un corredor, iluminado con luz natural por cuatro pequeños patios ajardinados situados en su tramo central. Los servicios comunes de apoyo se disponen en la parte interior y a lo largo de las fachadas los laboratorios de los departamentos de investigación, independientes entre sí, pero manteniendo cierta continuidad al haberse incorporado un plano acristalado en la parte superior de los tabiques.

Las dependencias de uso más público quedan alojadas en un cuerpo más reducido de geometría irregular y mayor elevación, que dibuja un acusado ángulo agudo en el flanco norte. Su diseño, con planos imbricados y una mayor diversificación en los huecos, se aleja de cualquier simetría. En el frente de la cafetería, orientado al este, se abre una terraza en la que los elementos arquitectónicos enmarcan el paisaje, que es observado por el espectador como si fuese un cuadro, un recurso empleado con frecuencia por Joao Alvaro Rocha ${ }^{11}$. En el lado opuesto llama la atención el gran mirador angular que enfoca nuestra visión hacia el área biosanitaria del campus, desde un luminoso interior concebido como una relajante área de descanso.

Uno de los aspectos más atractivos del edificio es el amplio vestíbulo que estructura este bloque, concebido como un vacío a triple altura iluminado cenitalmente por un lucernario cónico y atravesado en diagonal por una airosa y diáfana escalera de trazado recto.

\footnotetext{
${ }^{11}$ Cañizal (2009), 2, 765.
} 


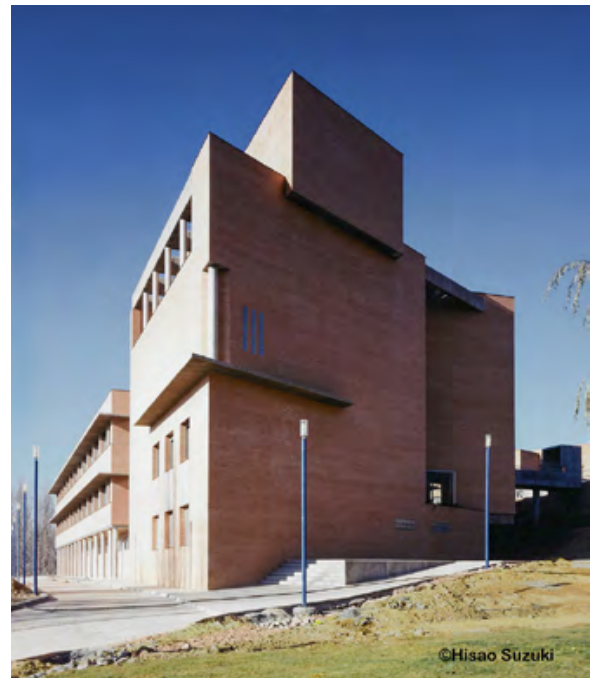

La unión de ambos volúmenes se efectúa a la altura de una pasarela de hormigón, precedida por un cubo similar a los diseñados en ladrillo por Cano Lasso en la Facultad de Farmacia, que conduce al ingreso principal situado en la tercera planta para salvar el desnivel con respecto al campus, de manera que solo parte del edificio es visible desde éste. Delante del acceso se configuró una pequeña plaza peatonal y se ajardinó el entorno, un aspecto al que se concedía especial importancia en el Proyecto de Humanización del Campus Miguel de Unamuno, realizado en 1998 por el propio Emilio Sánchez ${ }^{12}$. Una vía rodada paralela al nivel inferior del inmueble permite llegar a otra entrada de servicio situada en su extremo sur.

Al igual que en las facultades inmediatas, en el exterior se emplea ladrillo cerámico con carpintería de aluminio lacado, que sirve de elemento unificador del conjunto. Su volumetría solo es patente en la fachada oriental, con un pórtico columnado en el bajo del bloque rectangular en oposición al que se abre en la parte superior del segundo, y acusados aleros a modo de viseras sobre los vanos horizontales, que rompen la monotonía del cierre y proporcionan mayor plasticidad.

${ }^{12}$ Cañizal (2009), 1, 230. También intervino en la redacción del Plan Especial de Reforma Interior del nuevo Recinto Universitario de Salamanca (PERI 1985). 


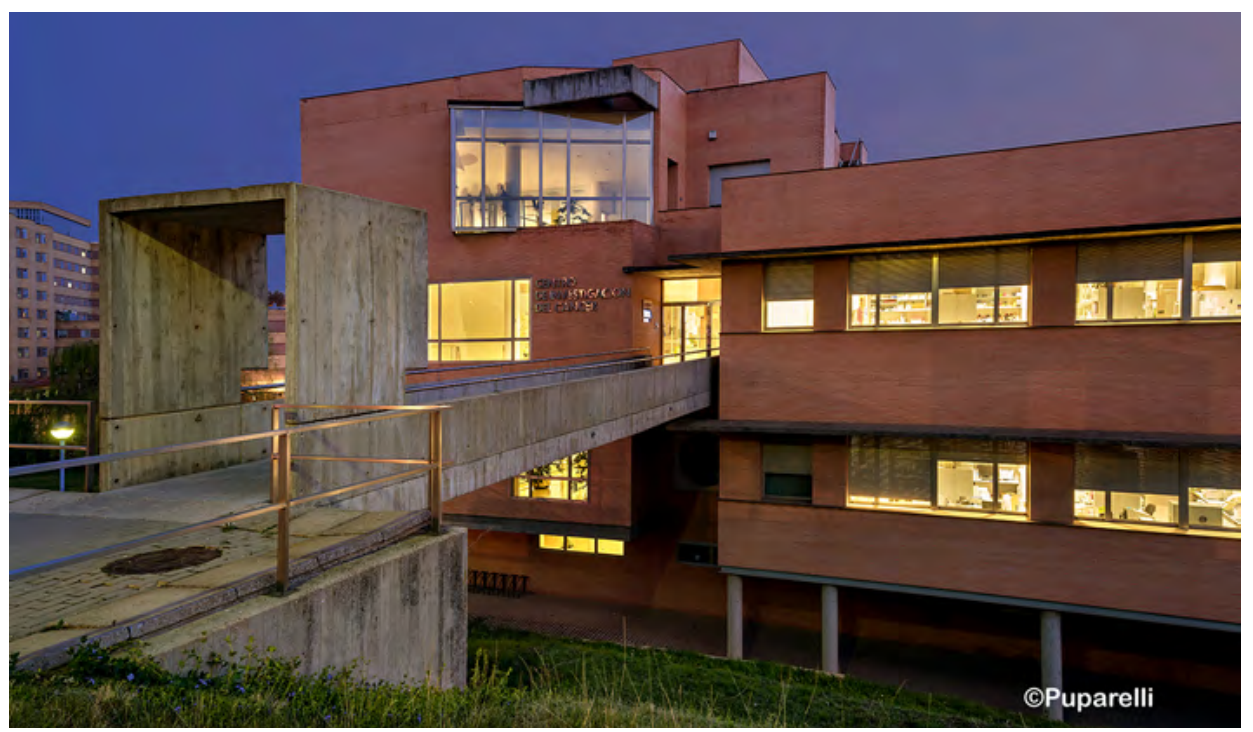

En 1999 se incorporó en los sótanos un laboratorio de alta seguridad biológico ${ }^{13}$ y se decidió construir un nuevo animalario transgénico entre la Facultad de Farmacia y el Centro del Cáncer, con el que se comunicaría a través de dos túneles desde la planta -3. El Ministerio de Educación y Ciencia destinó para este fin una partida de cuatro millones y medio de euros ${ }^{14}$.

De nuevo, se eligió la propuesta presentada por Emilio Sánchez Gil. Se trata en este caso de un edificio pequeño de gran complejidad técnica, pero de gran sencillez arquitectónica. Los laboratorios, despachos y almacenes se desarrollan bajo tierra en dos niveles, mientras al exterior solo es visible la planta de acceso, en la que se usa ladrillo visto como en los edificios del entorno, con el cuerpo de ventilación a modo de torre perforada con lamas metálicas como única nota de variedad. Entró en funcionamiento a finales de 2005 y depende hoy día del Instituto de Investigación Biomédica de Salamanca (IBSAL), constituido en $2011^{15}$.

Ese año se falló también en favor de Sánchez Gil el concurso de ideas para construir el Centro de Caracterización de Recursos Biológicos ${ }^{16}$ entre el Instituto del Cáncer y el edificio Dioscórides. La falta de presupuesto ha

${ }^{13}$ En este caso el arquitecto de la Unidad Técnica Luis Ferreira realizó el proyecto complementario.

${ }^{14}$ Cañizal (2009), 2, 768-769. La USAL tiene actualmente otros dos animalarios: en Neurociencias y en el Edificio Departamental de Biología.

${ }^{15}$ https://ibsal.es/es/ [citado el 6 de abril 2020].

${ }^{16}$ La Gaceta de Salamanca, 7 de octubre 2011. 
impedido, sin embargo, acometer este proyecto que habría supuesto la ampliación del Banco Nacional de ADN.

Instituto de Neurociencias de Castilla y León (INCYL)

El Instituto de Neurociencias de Castilla y León forma parte de una red nacional dedicada a la investigación de patologías del sistema nervioso y al tratamiento de enfermedades neurológicas y mentales ${ }^{17}$. Se creó en 1998 y aglutina buena parte de la actividad desarrollada en este campo en esta comunidad autónoma.

Para poder levantar un edificio adecuado a sus necesidades se destinó una parcela cedida a la Universidad por el Ayuntamiento de Salamanca, situada en las inmediaciones del cementerio y relativamente cercana al área biosanitaria del campus Unamuno. Los autores del proyecto seleccionado en 2004 fueron Juan Vicente García y Pablo Núñez Paz ${ }^{18}$. En él, además de los requisitos técnicos adelantados por la Unidad Técnica, tuvieron muy en cuenta la situación urbana del entorno y, en especial, la topografía originaria. Propusieron en consecuencia un edificio extraño a la anodina ocupación colindante de uso residencial que, por su situación a la entrada oeste de Salamanca, pudiera constituirse en signo visible del estudio y la investigación identitarios de esta ciudad.

Su configuración es fruto de una profunda reflexión sobre la relación naturaleza-arquitectura, que para estos arquitectos es una cuestión ineludible
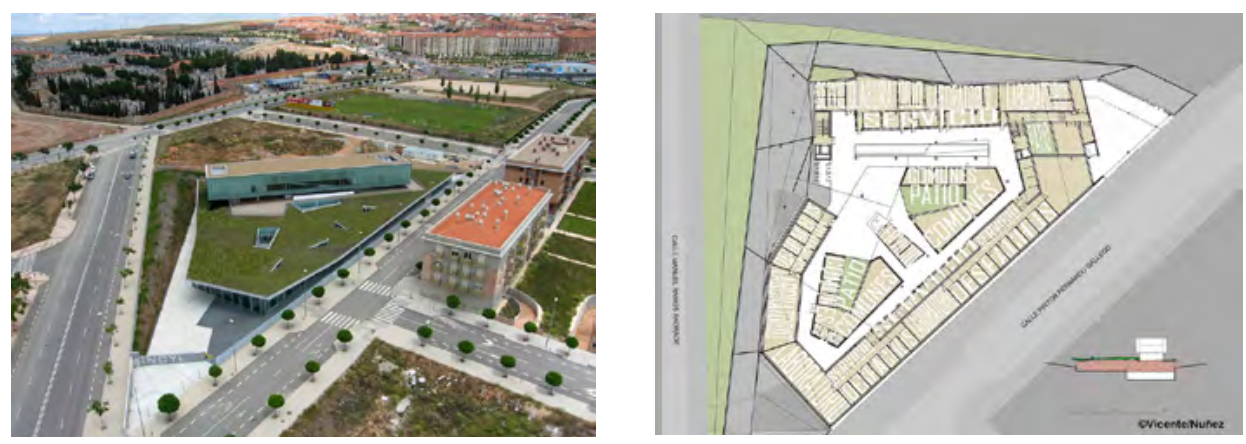

${ }^{17}$ Realiza también tareas de formación de nuevos investigadores y una labor de divulgación científica: https://institutoneurociencias.org/ [citado el 29 de abril 2020].

${ }^{18}$ Forman un equipo que ha sido reiteradamente premiado a nivel nacional e internacional. En 1999 ganaron el concurso para construir en esta Universidad la R.U. Colegio de Cuenca. 
a la hora de proyectar. Según reconocen, para su propuesta resultaron inspiradoras algunas intervenciones en el paisaje de artistas contemporáneos, como las Surrounded islands de Christo y Jeanne-Claude en la bahía de Florida o la obra Displaced/Replaced Mass 1 de Michael Heizer en el desierto de Nevada, así como la continuidad e interrupción que producen las ha-ha de los jardines británicos ${ }^{19}$. La estrategia adoptada fue ocultar el programa principal bajo un jardín-plataforma que sirve de marco a un prisma vítreo que se alza en la parte más elevada de la parcela y constituye la imagen reconocible del conjunto. Era una manera de rellenar el hueco dejado por la urbanización en el solar, dando cuenta del perfil y la vegetación originarios. Por otra parte, se acusa el perímetro de terreno mediante una fisura que establece el encuentro de la plataforma con las nuevas calles, afirmando a la vez su presencia. Este corte perimetral permite iluminar las dependencias interiores y resolver los accesos.

Bajo la cubierta ajardinada se sitúan los laboratorios de los grupos de investigación, con despachos para los responsables, en el anillo y hacia el interior los de apoyo o uso común, manteniendo la interrelación entre las
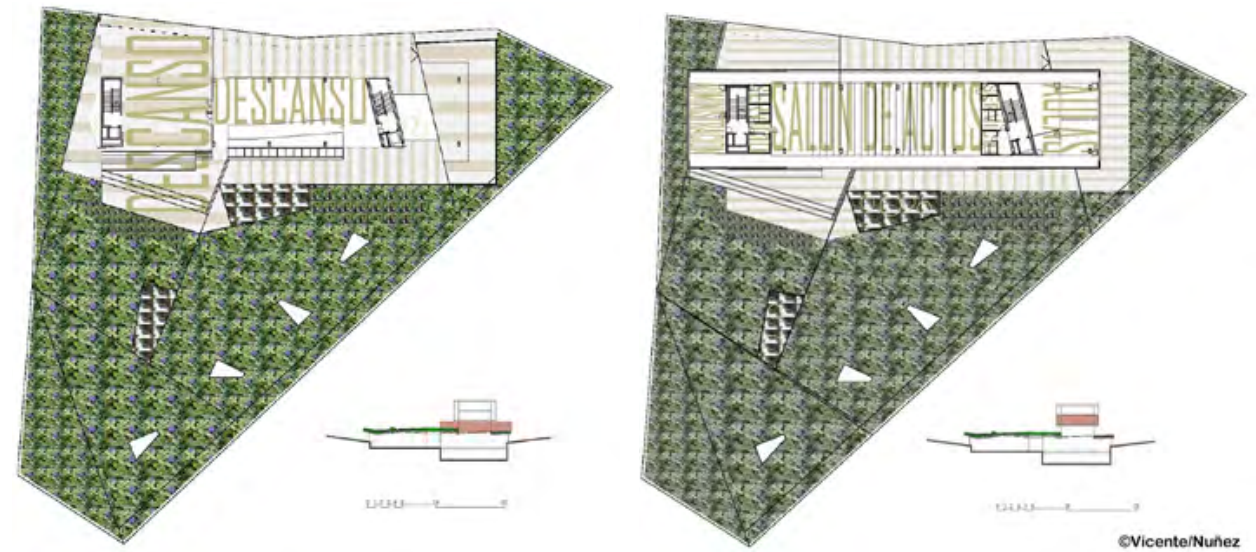

${ }^{19}$ Juan Vicente y Pablo Núñez, Memoria del Instituto de Neurociencias de Castilla y León, s. f. (facilitada por los autores). En las publicaciones suelen recogerse los aspectos más descriptivos del edificio omitiendo este trasfondo conceptual. Pablo Núñez Paz y Juan Vicente García, "Análisis. Instituto de Neurociencias de Castilla y León", Pasajes. Arquitectura y crítica, 96 (2008), 30-37. Silvio Carta, "Vicente/Núñez, Neuroscience Institute in Castilla y León", C3, 311 (2010), 184-194. Pablo Núñez Paz y Juan Vicente García, "Instituto de Neurociencias de Castilla y León", 02 abril 2012. Plataforma Arquitectura [citado el 7 de mayo 2020]: disponible en https://www.plataformaarquitectura.cl/cl/02-149168/instituto-de-neurocienciasde-castilla-y-leon-canvas-arquitectos. 
diversas áreas. En el sótano se encuentran los talleres y almacenes, así como el animalario y otros elementos que requieren aislamiento y protección de la luz natural.

La entrada principal se realiza a través de un gran atrio bajo la estructura de hormigón de la plataforma, que conduce a un amplio vestíbulo con rampa de acceso al nivel de la cubierta, que aporta dinamismo a este espacio. Dos grandes patios proporcionan luz natural a toda la planta, en la que la vegetación convive con los juegos de color de los revestimientos articulando un paisaje interior complejo.
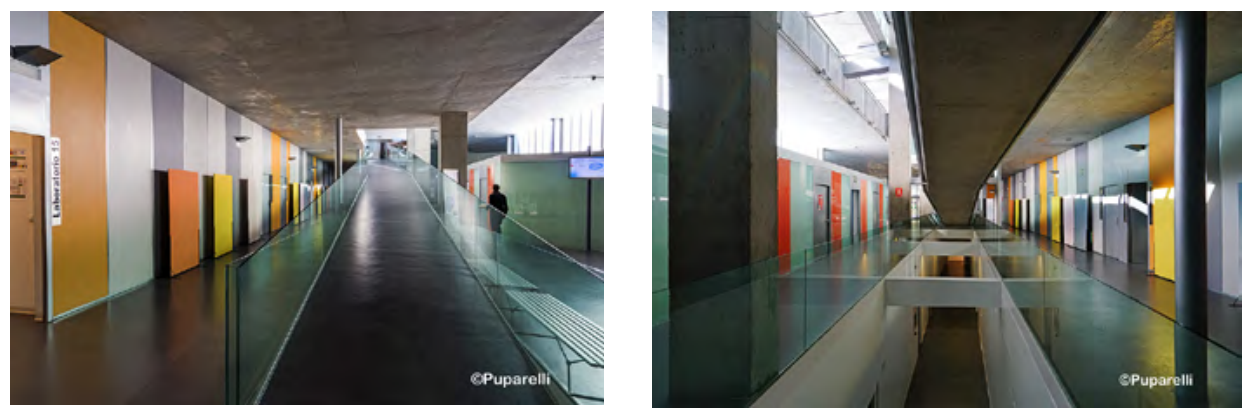

Sobre la cubierta, un porche con una pequeña zona acristalada de esparcimiento da paso al jardín y a la caja de cristal, nítida, que alberga las estancias de carácter administrativo y docente, con aulas de postgrado y un gran salón de actos. El artista Fernando Sinaga asesoró en el cerramiento de este volumen que fue objeto de un especial cuidado. En lugar de un muro inerte de vidrio transparente, como en su día utilizó Mies, se dispuso un sistema multicapas que además de ahorrar energía y abaratar el mantenimiento, dotan de un mayor valor expresivo a las cualidades lumínicas en la configuración del espacio. Así en el interior se usó una capa de "vidrio laminar con un velo interpuesto de fibra de vidrio que ofrece una imagen asimilable a tejido neuronal" que difumina la luz, mientras la cara exterior la conforma un vidrio con estrías, orientadas de forma distinta a lo largo de la fachada, que desvían la incidencia directa del sol y contribuyen a que la percepción sea arbitraria y dependa de la iluminación y de la posición del espectador, introduciendo, de manera consciente, un elemento humano que diluye el aparente carácter abstracto de la caja.

Los materiales de construcción propuestos buscaron simplificar al máximo la complejidad formal, con soluciones técnicas claras que permitiesen una fase de ejecución simple. Así, sobre la estructura principal de hormi- 


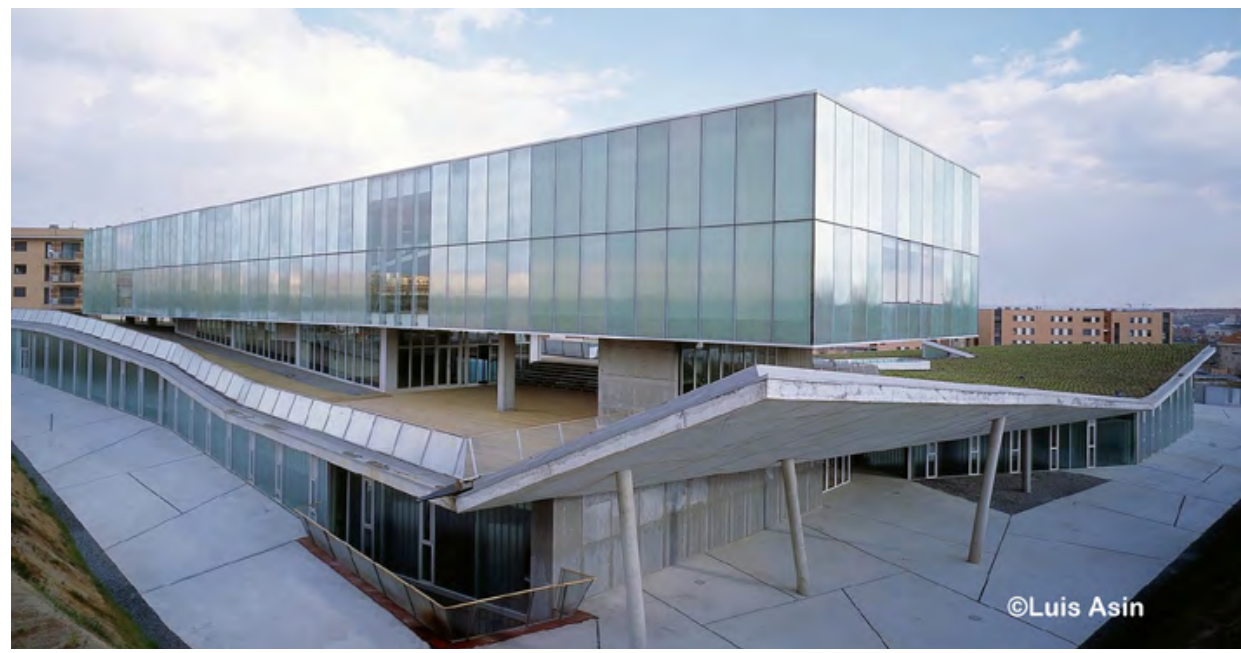

gón se aplicaron sistemas de cerramientos ligeros sobre estructuras metálicas, que facilitarían montajes rápidos y asimismo los cambios y adaptaciones constantes que suelen ser frecuentes en este tipo de edificios. Por su parte, el gran jardín de la azotea se resuelve con un sistema ecológico, utilizando especies resistentes a las estaciones y el riego por goteo de bajo consumo y mantenimiento. Este edificio constituye, en suma, un buen ejemplo no solo de arquitectura sostenible y funcional, sino también innovadora a partir del nuevo concepto de la construcción, integrada en el paisaje, defendido por los autores.

Las obras habían concluido en marzo de 2008, aunque la inauguración oficial tuvo lugar el 26 de febrero de 2009, con la asistencia de Juan Vicente Herrera, presidente de la Junta de Castilla y León. El presupuesto total ascendió a 6.997.342 euros, que fueron financiados por esta entidad y a través de fondos FEDER ${ }^{20}$.

Instituto de Biología Funcional y Genómica (IBFG)

El Instituto de Biología Funcional y Genómica (IBFG) es un centro mixto de investigación cuya titularidad comparten el CSIC y la Universidad de Salamanca.

${ }^{20}$ Europa Press, 26/02/2009 [citado el 6 de abril 2020]: disponible en https://www. europapress.es/nacional/noticia-herrera-inaugura-hoy-salamanca-instituto-neurocienciascastilla-leon-20090226091930.html 
Su punto de partida fue el Instituto de Microbiología-Bioquímica (IMB), vinculado al departamento de Microbiología fundado en 1970 por el catedrático Julio Rodríguez Villanueva. El IMB fue uno de los primeros institutos mixtos de investigación. Al principio su actividad se centró fundamentalmente en la Biología, pero desde 1985 comenzaron a consolidarse grupos de investigación dedicados a las áreas de Biología Molecular y Celular ${ }^{21}$.

Tuvo su sede inicialmente en la Facultad de Ciencias y desde 1993 en el Edificio Departamental de Biología del campus Miguel de Unamuno. En 2004 el IMB se desvinculó del departamento de Microbiología y Genética y empezó a plantearse la necesidad de disponer de unas instalaciones propias con las condiciones adecuadas para ampliar e impulsar la investigación, con grupos cada vez más numerosos.

Las gestiones con este objetivo llegaron a buen término y en septiembre de 2007 se aprobó el proyecto del nuevo edificio, seleccionado por concurso público, cuya construcción costearía el CSIC a través de los Presupuestos Generales del Estado ${ }^{22}$. Por su parte, la Universidad de Salamanca le cedió en 2008 la parcela inmediata al Instituto de Neurociencias de Castilla y León para su ubicación ${ }^{23}$. En marzo de ese año salió a licitación la obra y en agosto comenzaba la construcción ${ }^{24}$.

El diseño ganador se debe a Salvador Mata Pérez y su estudio, especializado desde 2001 en que proyectó el Instituto de Biología Genética y Molecular (IBGM) de la Universidad de Valladolid, en centros I+D+i y en edificios del ámbito sanitario ${ }^{25}$. En este caso, la solución propuesta es un gran volumen rectangular, unitario y compacto, de cuatro plantas, con una "máscara continua y semitransparente inspirada -según el autor- en los procesos de codificación genética", que oculta el interior ${ }^{26}$. En contraste con la base de

${ }^{21}$ Una breve historia en la web del Instituto en: https://ibfg.usal-csic.es/presentacion. html [citado: 6 de abril 2020].

${ }^{22}$ BOE, 4/07/2007. La aportación del Ministerio de Educación y Ciencia fue de 9,3 millones, con una primera partida para su construcción y equipamiento en el ejercicio de 2006 y la última en 2010. El programa de necesidades especificado por el CSIC se publicó en el BOE de 26 de febrero de 2007.

${ }^{23}$ Instituto de Microbiología Bioquímica. Memoria de Curso 2007-2008, 2. DiCYT, Agencia Iberoamericana para la difusión de la ciencia y la tecnología, 22/07/2008 [citado el 5 de abril 2020]: disponible en https://www.dicyt.com/viewNews.php?newsId=11008

${ }^{24}$ BOE, 6/03/2008.

${ }^{25}$ ArquitecturaVA: Mapa ampliado de Arquitectura Moderna de Valladolid. Disponible en: https://arquitecturava.es/proyectos-valladolid/instituto-de-biologia-y-genetica-molecularibgm/ [citado el 5 de abril 2020].

26 “Instituto de Biología Funcional y Genómica / Mata y Asociados" 28 nov 2012. Platafor- 


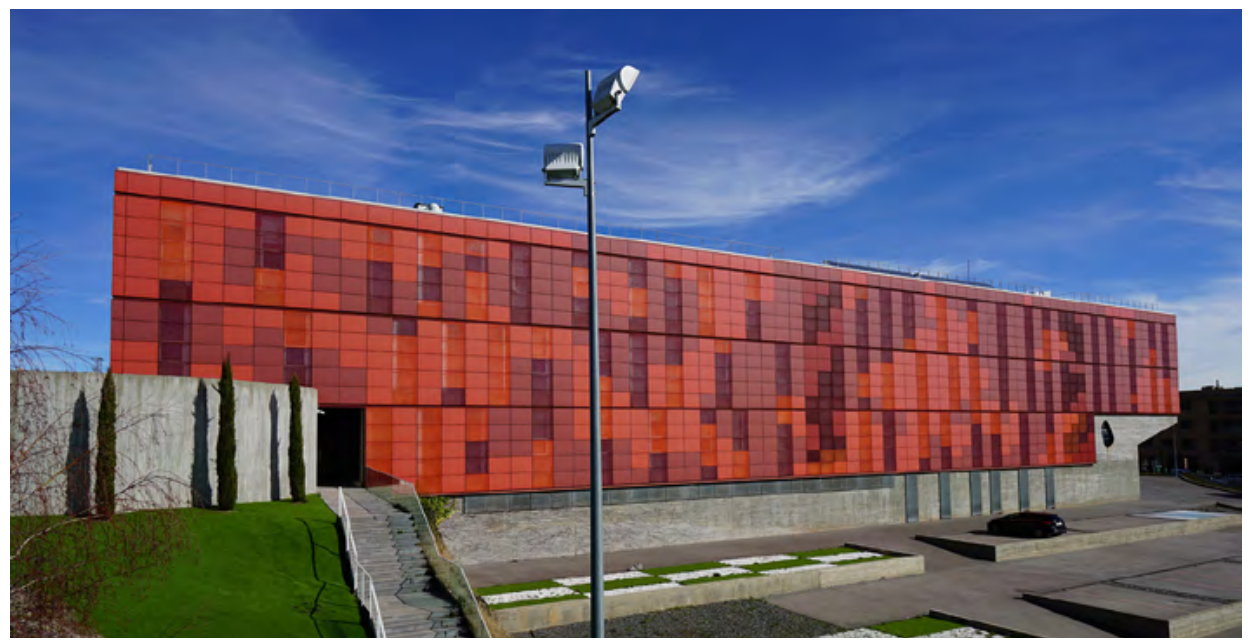

hormigón, el panelado en distintas tonalidades de rojo usado en el exterior proporciona al inmueble una llamativa apariencia, que se impone abiertamente en su entorno. Se buscaba en este caso ofrecer una imagen representativa, aunque quizá pocos asociarán ahora estos tonos con los colores de los logos institucionales tanto de la USAL como del CSIC, en los que se inspiró el arquitecto cuando propuso ese acabado, que ha llevado a que se le conozca como el "edificio rojo".

Como es frecuente en esta tipología, el programa funcional se organiza simétricamente a ambos lados de un corredor central, pero se introducen ocho grandes perforaciones verticales, cuatro hacia el interior y cuatro contrafachadas en los flancos longitudinales, para dotar al interior de luz natural, aunque la luminosidad es limitada. En las dos plantas superiores se ubican la mayor parte de los laboratorios de apoyo, los de investigación y los despachos. En el bajo, además de la zona de administración, se concentran los espacios dedicados a la docencia, con varios tipos de aulas, una sala de juntas, el salón de actos y algún laboratorio más, mientras en el semisótano se localizan distintos almacenes, talleres, laboratorios comunes y otros servicios específicos.

En el vestíbulo principal y en algún otro punto, como parte de la ambientación interior, se distribuyen suspendidos en el espacio, dibujos lineales en tubos de neón de formas irregulares, a modo de esculturas aéreas que 
evocan el aspecto de algunos microorganismos. El precedente podemos encontrarlo en el bucle de neón con líneas curvas entrecruzadas instalado por Lucio Fontana en el techo de la escalera del Palazzo dell'Arte de Milán en 1951. En la decoración juegan, asimismo, un papel destacado las diferencias cromáticas aplicadas a suelos, paredes y techos, y la disposición de los vanos, en especial las grandes ventanas verticales del vestíbulo frente a la escalera, concebida con una ligera estructura exenta de doble tramo, mientras el tratamiento del muro remite a las tarjetas perforadas de ordenadores, según creación de Fernando Guijar.

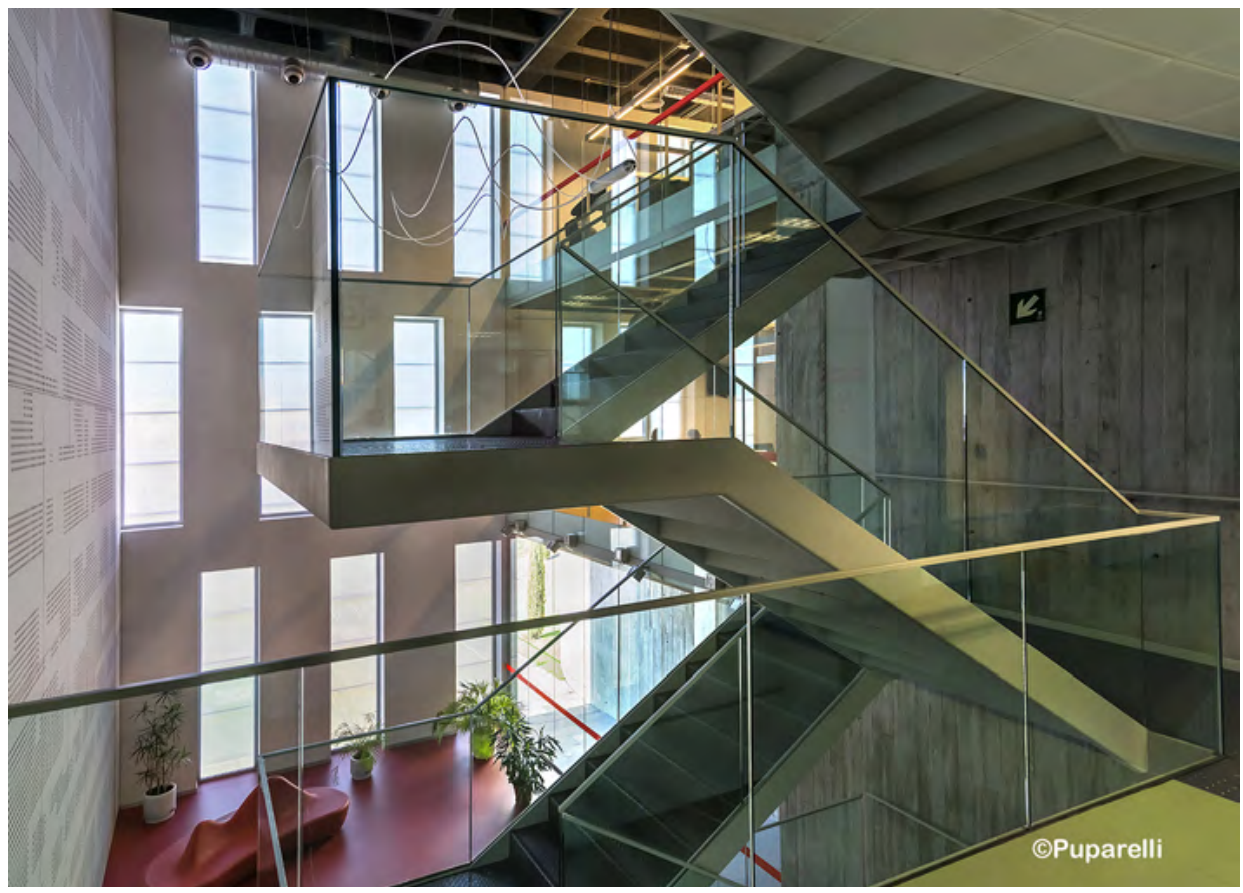

Teniendo en cuenta el acusado desnivel del solar, el acceso más representativo se colocó en la cota superior, en la cabecera norte, flanqueado por una forma orgánica en hormigón de tipo "ameboide" que emerge del bloque, correspondiente al salón de actos. En el extremo opuesto hay otra entrada vehicular para carga y descarga bajo grandes ménsulas también de hormigón, precedida de un patio. Dada la compactación del programa, en la parte del solar que quedó libre inmediato a Neurociencias, se proyectó una sucesión de bandejas escalonadas, con zonas ajardinadas y bandas de estacionamiento controlado de vehículos, con el fin de crear un área de esparcimiento. 
Los trabajos se prolongaron hasta marzo de 2012. Al trasladarse a su nueva sede el IMB pasó a llamarse Instituto de Biología Funcional y Genómica (IBFG), dado que el nuevo centro contemplaba una mayor diversificación en el estudio de sistemas biológicos y la incorporación de otros grupos de trabajo dedicados a la biología celular, molecular y genómica.

\section{Urbanismo y arquitectura del campus de Villamayor}

Como parte del Plan Estratégico, al comienzo del rectorado de Enrique Battaner en 2003 se plantea la conveniencia de expandirse a nuevos espacios físicos para responder a los retos que suponía el Espacio Europeo de Educación Superior en cuanto a la relación universidad empresa, la investigación y la docencia. Las gestiones realizadas con este fin culminaron en la firma en 23 de junio de 2004 de un convenio marco de colaboración, por el que el Ayuntamiento de Villamayor de la Armuña cedía a la Universidad de Salamanca un amplio terreno -algo más de $300.000 \mathrm{~m}^{2}$ y unos $50.000 \mathrm{~m}^{2}$ de edificabilidaden la periferia suroeste de ese municipio ${ }^{27}$, situado a unos $5 \mathrm{~km}$ al oeste de esta ciudad y por lo tanto relativamente próximo al campus Miguel de Unamuno, con un grado de saturación ya notable.

Al mismo tiempo, para poder financiar este ambicioso proyecto, se sucedieron los contactos con la Junta de Castilla y León, el CSIC, entidades bancarias o empresas que pudieran estar interesadas en instalarse en los futuros edificios de este nuevo campus de Villamayor, como empieza a denominarse. A comienzos de 2005 quedó constituida la Fundación Parque Científico para favorecer la gestión y el desarrollo del mismo. Estaba presidida por el rector e integrada por representantes del Consejo Social, la Junta de Castilla y León, la Diputación, el Ayuntamiento y la Cámara de Comercio de Salamanca, el Ayuntamiento de Villamayor y el Banco Santander, que ofreció una importante donación económica con este $\operatorname{fin}^{28}$.

A corto plazo se decidió construir en este emplazamiento unas instalaciones adecuadas para el Instituto Hispano-Luso de Investigaciones Agrarias.

\footnotetext{
${ }^{27}$ Estos terrenos estaban ordenados por el Plan Parcial Sector 14. Miguel Ángel Moreno de Vega, Estudio de detalle para la modificación de las parcelas CS.EQ.01 del Parque Científico de la Universidad de Salamanca. Septiembre 2015. (20/05/2016 [citado el 14 de marzo 2020]. Junta de Castilla y León: disponible en http://www.jcyl.es/plaupdf//37/37354/292962/DOCUMENTO.pdf

${ }^{28}$ Juan Manuel Corchado, Diez años del Parque Científico de la Universidad de Salamanca (Salamanca: Ediciones Universidad Salamanca, 2016), 18-19.
} 


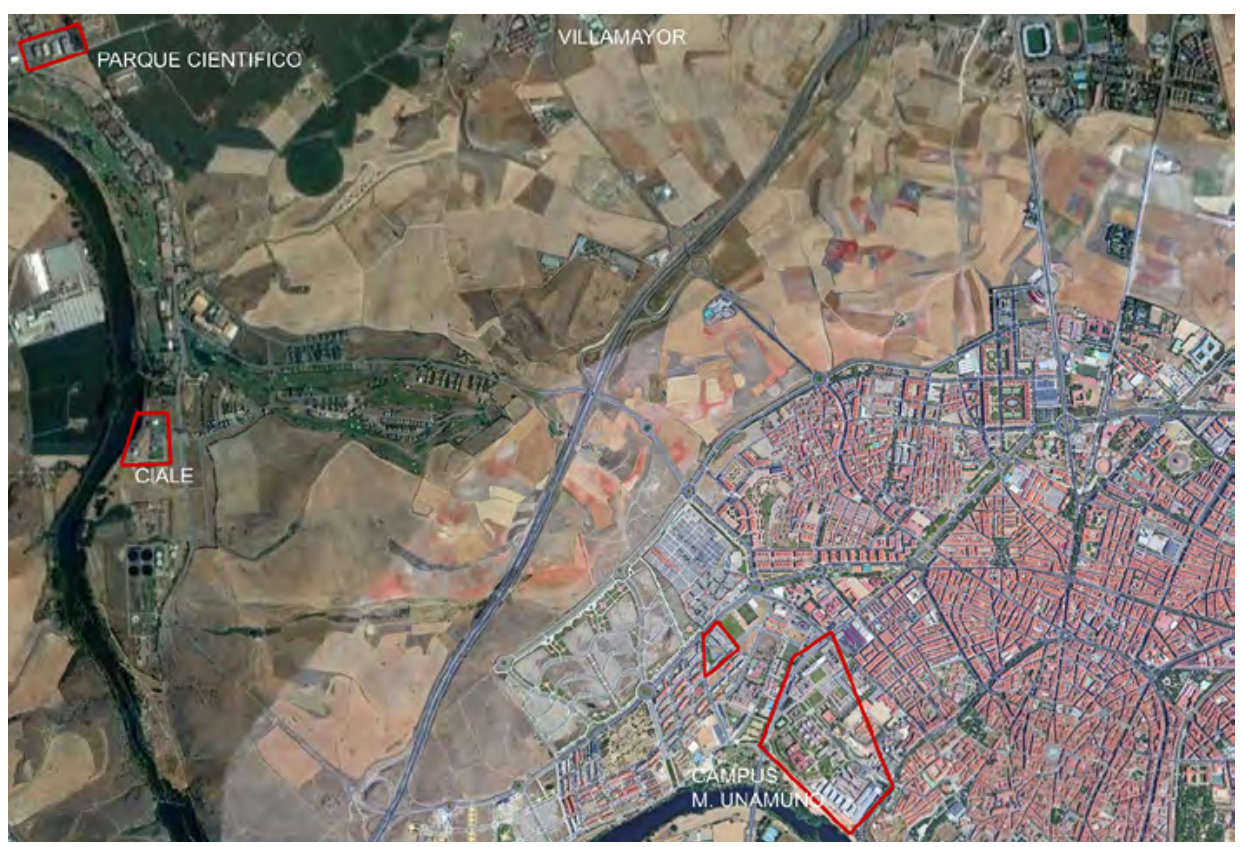

Instituto Hispano-Luso de Investigaciones Agrarias (CIALE). Invernadero e Incubadora de Empresas

El CIALE es un centro puntero que aglutina la investigación y experimentación agrícola que desarrolla la Usal, con las tecnologías más innovadoras, dentro de los ámbitos de la biodiversidad, mejora genética, producción vegetal, sanidad vegetal o recursos hídricos, con el fin de conseguir una agricultura moderna, sostenible y de alto rendimiento. Proporciona, asimismo, formación especializada en técnicas y procesos agrobiológicos y organiza actividades dirigidas a un mejor conocimiento de los aspectos agrícolas implicados en el desarrollo socioeconómico de Castilla y León ${ }^{29}$.

Este centro de investigación se puso en marcha en el año 2000 pero carecía de infraestructuras propias. Con este propósito se convocó un concurso de ideas que incluyó también la proyección de una nueva Facultad de Ciencias Agrarias y Ambientales, dadas las notables deficiencias de su inmueble.

De nuevo el proyecto seleccionado fue el presentado por Juan Vicente y Pablo Núñez, los mismos arquitectos del Instituto de Neurociencias. Como es habitual en ellos, tuvieron muy en cuenta en su diseño el emplazamiento,

${ }^{29}$ Para más información: https://ciale.usal.es/ 
además de los requisitos tecnológicos del centro. Se había destinado para este fin un terreno inmediato al Tormes de gran interés ambiental. Partiendo del estudio geológico plantearon una construcción que, en lugar de imponerse, se integrase plenamente en el paisaje, del que en cierto modo se podría decir que emerge ${ }^{30}$.

Así, en el nivel superior, donde se ubican los accesos desde la calle, la edificación de planta alargada que acoge el programa de investigación y las instalaciones de apoyo de uso común, se funde prácticamente con el entorno al quedar semienterrada bajo una cubierta ajardinada. A través de una rampa se llega al vestíbulo que atraviesa y articula el conjunto, iluminado por dos grandes patios que proporcionan luz natural a toda la planta y permiten percibir sobre los laboratorios las plegaduras de hormigón de la cubierta, en contraste con los juegos de color de los revestimientos.

Los laboratorios están situados en el nivel inferior y orientan sus vistas al río. Ocupan cuatro cubos con cubierta también vegetal, levantados sobre una estructura de pilotes para aislarlos de posibles avenidas fluviales. Se disponen de manera libre alrededor de una serie de patios abiertos, de forma que están en contacto con el terreno pudiendo realizar en él una prolongación física de su actividad. Dado que uno de los objetivos del diseño era conseguir permeabilidad y transparencia entre la edificación y el paisaje, se plantearon sistemas de cerramiento ligeros, que matizan las necesidades de soleamiento y privacidad necesaria. El esquema aplicado, flexible y versátil,

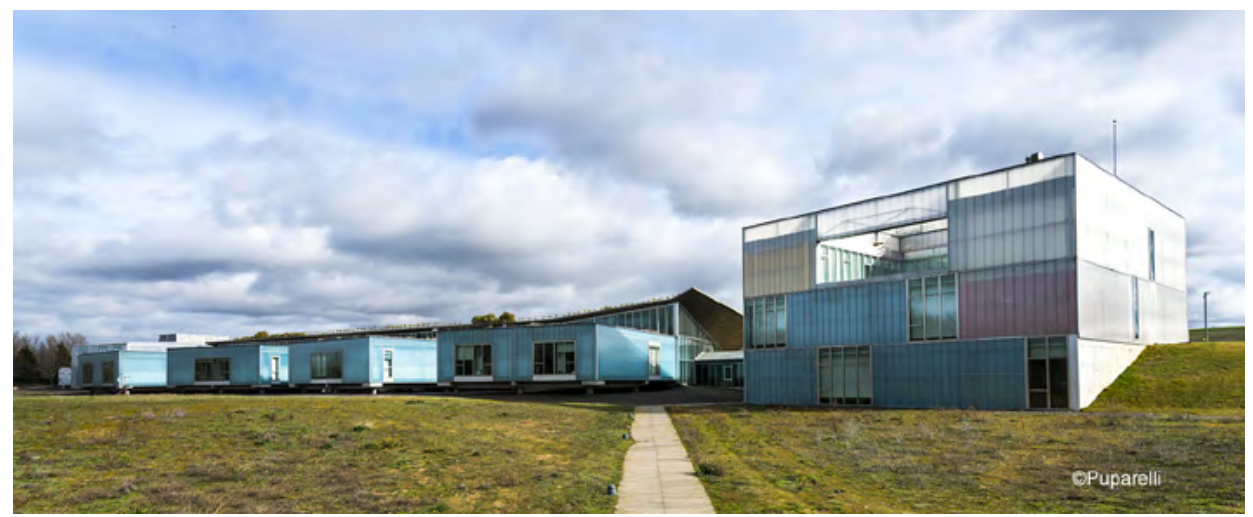

${ }^{30}$ Sobre el edificio, véase: Pablo Núñez Paz, Juan Vicente García, “Centro Hispano-Luso de Investigaciones Agrarias (C.I.A.L.E.)", Pasajes. Arquitectura y crítica, 105 (2009), 14-15. Silvio Carta, "Vicente/Núñez, Portuguese Agricultural Research Center-Ciale", C3, 311 (2010), 194203. Vicente/Núñez arquitectos, "CIALE. Centro hispano luso de Salamanca”, en Manuel Rúa García (ed.), Síntesis Arquitectura. Castilla y León (Madrid: 2011), 14-35. 

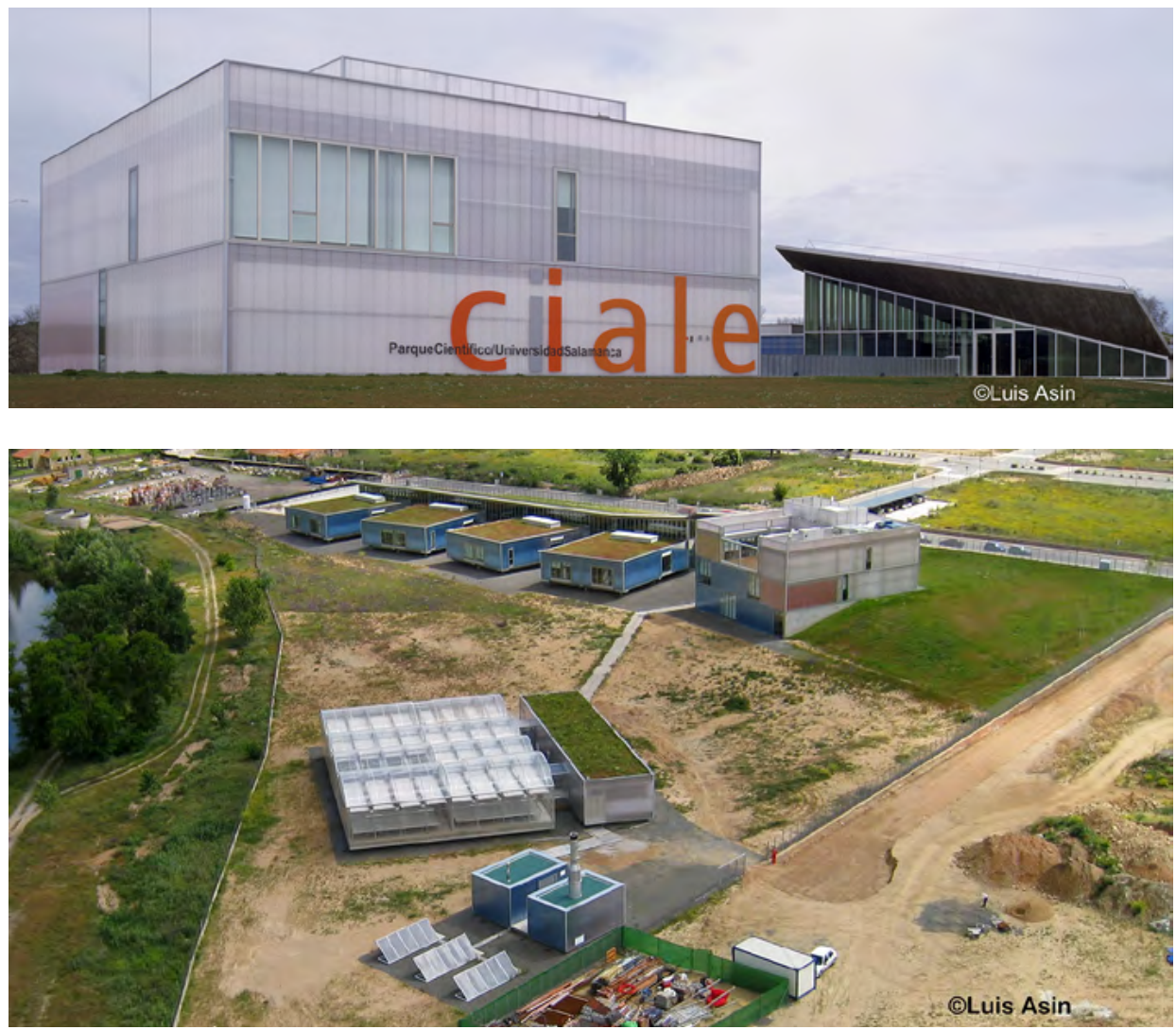

posibilita que en el futuro se puedan incorporar nuevos programas al complejo de investigación. En definitiva, se propuso -en palabras de los autores"una arquitectura bioclimática y sostenible, relacionada con la tierra, para lograr de manera pasiva unas favorables condiciones medioambientales".

El jardín plataforma, con especies resistentes de floración estacional y riego por goteo, sirve de marco a un prisma vítreo que se alza en la parte más alta de la parcela y constituye la imagen reconocible del conjunto. El nombre graficado en él informa de la naturaleza de la construcción. Esta caja, comunicada por un corredor interno con el otro módulo, alberga las dependencias administrativas y docentes, con despachos, un salón de actos, aulas de posgrado y biblioteca. El cerramiento de este volumen, como en Neurociencias, está compuesto por dos capas: la interior conformada por un vidrio laminar que difumina la luz, mientras en la cara exterior se empleó un vidrio con estrías, orientadas de forma distinta a lo largo de la fachada, que desvían la incidencia directa del sol y particularizan el muro cortina según el punto de observación. 
Las obras del CIALE se iniciaron el 29 de diciembre de 2004 a cargo de la empresa Dragados y Construcciones y se prolongaron durante más de dos años. Su financiación, con un presupuesto inicial de 3.205.039€, fue costeada por la Fundación del Parque Científico.

Asumió, asimismo, con la ayuda de fondos FEDER, la construcción del Invernadero que se planteó en 2005, una vez comenzado el CIALE. Se buscó que ambas infraestructuras tuviesen un carácter conjunto, estableciéndose la conexión entre ellas a través de un camino peatonal desde el CIALE hasta el acceso principal del Invernadero, en el lado norte. Esta instalación está integrada por dos tipos de construcciones. Por un lado, el invernadero propiamente dicho, de $20 \times 28,8 \mathrm{~m}$, constituido por una estructura tipo multitunel cerrada con policarbonato e integrado, a su vez, por ocho módulos independientes, con sistema de control medioambiental automatizado, incluyendo riego por goteo, dispersión de agua, calefacción e iluminación artificial. Uno de esos módulos, con seguridad especial, está dedicado al cultivo de plantas transgénicas. Estos espacios han sido diseñados con un alto nivel técnico y constructivo para garantizar un área de gran calidad para los trabajos de investigación. Por otro lado, hay un pequeño anexo de instalaciones y manipulación con sala de preparación de muestras, almacén, despachos y otros servicios $^{31}$. Este invernadero experimental, clave para las empresas biotecnológicas, entró en funcionamiento en 2010.

En este mismo Enclave Agrobiotech se proyectó construir a finales de este último año una Bioincubadora ${ }^{32}$. Esta nueva infraestructura perseguía favorecer la transferencia de conocimiento y el desarrollo científico y empresarial, al poner a disposición de las empresas del sector "bio" equipos tecnológicos de última generación. Entraría así a formar parte de la red de bioincubadoras construidas en Castilla y León, como parte de una estrategia regional destinada a favorecer la incorporación de esta Comunidad a la red de Bioregiones europeas. Sin embargo, después se abandonó esta idea inicial y se amplió la oferta a compañías de otros ámbitos de conocimiento, spin off y start up surgidas de las actividades de investigación de la Universidad, por lo que pasó a denominarse Incubadora de Empresas $^{33}$.

El edificio fue financiado por el Ministerio de Ciencia e Innovación y supuso una inversión de casi dos millones de euros. Se dispuso en el espacio que ocupaba anteriormente el aparcamiento del Centro Hispano Luso de Investiga-

${ }^{31}$ Fundación Parque Científico. Memoria de actividades 2007-2008. Disponible en: http:// campus.usal.es/ memoria0607/0708/14_Fundaciones/14_2_Fundacion_Parque_Cientifico.html

${ }^{32}$ Fundación Parque Científico. Memoria de actividades 2009-2010, 7.

${ }^{33}$ Corchado (2016), 30-32. 

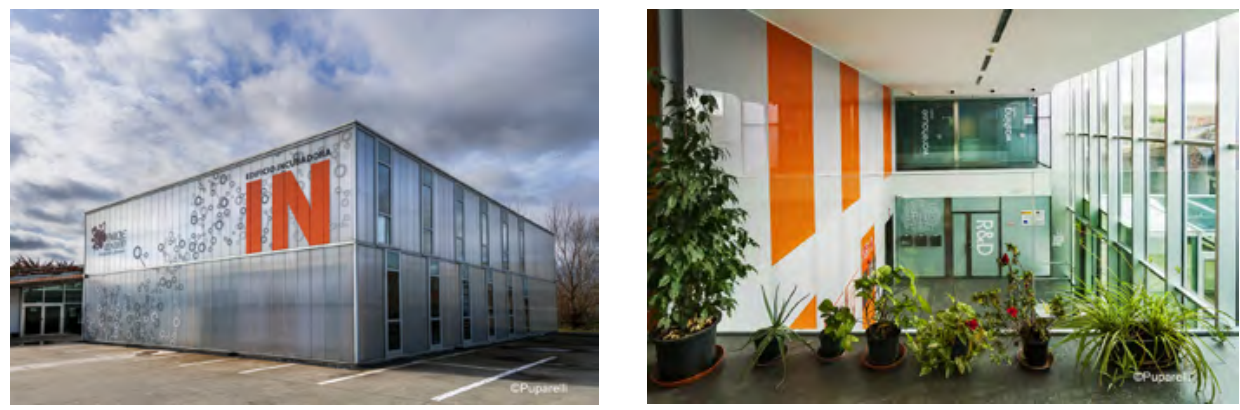

ciones Agrarias, con el que está unido por un corredor. Se buscó armonizar su arquitectura con la del cubo del CIALE situado en el extremo opuesto, usando doble capa de vidrio en el cerramiento externo. Consta de dos plantas con seis laboratorios, diez despachos y otros espacios de investigación, que estaban totalmente ocupados poco después de su inauguración, en septiembre de $2011^{34}$.

Plan Director del campus de Villamayor

Poco después de haberse iniciado el primer edificio del campus de Villamayor, el equipo de gobierno encargó la redacción de un plan director para este nuevo recinto universitario al profesor de la Universidad San Pablo-CEU Pablo Campos Calvo-Sotelo, conocido por sus estudios sobre arquitectura y urbanismo universitario. En este proyecto intentó satisfacer el decálogo de principios que, a su juicio, configurarían un "Campus Didáctico", un concepto elaborado por él, que define como una herramienta de "vocación práctica llamada a contribuir a impulsar procesos de transformación cualitativa de recintos universitarios" 35 .

Teniendo en cuenta que las parcelas cedidas por el municipio de Villamayor a la Universidad estaban separadas entre sí, con el río Tormes como único elemento unificador, propuso una estructuración del campus en tres

${ }^{34}$ Parque Científico de la Universidad de Salamanca. Memoria de actividades 2010-2011, 5-6.

35 Pablo Campos Calvo-Sotelo, El paradigma del "Campus Didáctico": revisión conceptual y proyección en los espacios físicos de la Universidad. (Salamanca: Ediciones de la Universidad de Salamanca, 2017), 112 y 118-386. Esos principios serían: 1.-Utopía y planificación integral. 2.-Comunidad de aprendizaje e investigación. 3.-Armonía espacial. 4.-Envoltura afectivo-intelectual. 5.-Naturaleza y Arte. 6.-Imagen y accesibilidad. 7.-Adaptación al medio y sostenibilidad. 8.-Memoria y vanguardia. 9.-Relación Universidad-Ciudad. 10.-Modalidades innovadoras de Enseñanza/Aprendizaje. 
áreas $^{36}$. En la zona sur, donde se estaba edificando el CIALE, se desarrollaría un Centro Agrario-Ambiental, con la Facultad de Ciencias Agrarias y Ambientales, campos de cultivos con canales de regadío; invernaderos; paseo de ribera y parque ripario e instalaciones deportivas generales.

En el norte se situaría un Centro de Comunicación y Arte, que incluiría, entre otras propuestas, una Facultad de Comunicación y usos asociados al Arte, como un "Espacio del Arte y la Cultura, formado por Jardín de las Artes, viviendas-taller de artistas y vinculado al Parque Temático de la Piedra e Itinerario Geológico". Y en el sector este, el único sin contacto con el río, se establecería el Parque Científico, con centros de investigación-tecnológicos, espacios para empresas -algunas en relación con el "entorno científico de las Ciencias de la Tierra"- o el "Instituto Geológico y Minero de España”.

Por lo que respecta a la configuración de estas áreas el plan director fijaba como principal criterio de intervención la "aspiración de calidad y vanguardismo". Un principio a valorar sería el que las diferentes piezas arquitectónicas, dentro de su singularidad, guardasen cierta homogeneidad o uniformidad en sus tipologías, en sus volumetrías, lenguaje arquitectónico y materiales, "para formar un conjunto coherente" donde cristalizase la máxima de "unidad en la diversidad". Calvo-Sotelo sugiere inspirarse para el diseño del nuevo campus "en estímulos proyectuales extraídos de la cultura local: el claustro, la plaza Mayor y la plasticidad de la legendaria piedra franca de Villamayor".

Un elemento esencial de esta composición urbanístico-arquitectónica serían los espacios libres y la comunicación. En este sentido, para aprovechar el excepcional entorno natural, plantea el diseño de un parque que transcurriría por la ribera del Tormes, desde la zona sur hasta el norte, con la utilización del río para actividades deportivas, lúdicas o formativas (como el conocimiento del entorno histórico y natural). Dentro del nuevo complejo universitario se daría protagonismo a los tránsitos peatonales, aunque la distancia con respecto al centro urbano de Salamanca y, por tanto, al núcleo principal de la Universidad, exigiría arbitrar un servicio rodado intercampus, utilizando las vías de comunicación ya definidas en el plan de ordenación del municipio donde se encontraban esos terrenos.

Se trataba en último término, como se ha señalado, de forjar un "campus didáctico", en el que la dimensión urbanístico-arquitectónica tuviese entidad

${ }^{36}$ Los párrafos que entrecomillamos a continuación proceden del artículo de Pablo Campos Calvo-Sotelo, "Plan Director del nuevo recinto de la Universidad de Salamanca en Villamayor", Urban. Revista de Urbanística y Ordenación del Territorio, 11 (2006), 120-126. 
propia y contribuyese de manera esencial a la formación integral de los alumnos, trascendiendo su papel como mero contexto. Se estimaba que este complejo, una vez desarrollado, abarcase una población de unos 2.000 alumnos ${ }^{37}$.

Este ambicioso proyecto educativo recogido en el Plan Director, como se puede advertir, incluía una enorme carga de utopía, un concepto que según el autor era un primer criterio de innovación. Pero quizá por ello, a pesar de la buena acogida inicial en el momento en que se dio a conocer públicamente el 3 de abril de $2006^{38}$, hasta la fecha no ha ido mucho más allá de su formulación teórica ampliamente defendida y difundida a través de publicaciones, seminarios o conferencias, tanto dentro como fuera del país ${ }^{39}$.

Con la llegada en 2007 de un nuevo equipo de gobierno a la Universidad de Salamanca, se anunció la intención de reforzar la presencia en el campus de Villamayor de los institutos y unidades de investigación, mientras se evitaría de momento el traslado de centros docentes, incluida la Facultad de Ciencias Agrarias y Ambientales, para la que ya había proyectos ${ }^{40}$. Esta decisión dejaba sin contenido parte del Plan Director, pero se recogió su propuesta sobre el emplazamiento del Parque Científico.

\section{El Parque Científico: urbanización e inmuebles}

Como se ha apuntado, en 2005 quedó constituida la Fundación Parque Científico para favorecer su gestión y lograr el objetivo de que el Parque actuase como vivero de empresas de alta tecnología ligadas a la actividad investigadora de la Universidad de Salamanca, que impulsasen la dinamización industrial, económica y social del entorno y potenciasen la creación de riqueza y empleo. En ese año se fueron también perfilando las aportaciones y el papel que el gobierno regional tendría en el futuro Parque. Se estudiaron, asimismo, los créditos sin intereses que ofrecía el gobierno central, a través del Minis-

${ }^{37}$ Calvo-Sotelo (2017), 410.

${ }^{38}$ Elisa Muñoz Torres, Memoria de Actividades del Curso Académico 2005-2006. Universidad de Salamanca, Secretaría General, 2006, 125-126. Se citan diversos galardones que había ya obtenido este plan.

${ }^{39}$ Se recogen ampliamente en Calvo-Sotelo (2017), 413-417.

${ }^{40}$ En 2020 la nueva Facultad de Ciencias Agrarias y Ambientales se considera ya una prioridad inaplazable. Está previsto ubicarla en la zona de la Platina, relativamente cercana a los Institutos de Neurociencias y de Biología Funcional y al campus Miguel de Unamuno. Allí también se desea instalar una nueva sede del Instituto de Recursos Naturales y Agrobiología del CSIC, dando lugar a un campus o área agroambiental. La Gaceta de Salamanca, 19 de diciembre de 2019. Tribuna de Salamanca, 30 de octubre de 2018. 
terio de Educación y Ciencia, para poder costear las infraestructuras de los Parques Científicos y Tecnológicos que deseaba incrementar en España, aglutinados desde 1989 en la Asociación APTE ${ }^{41}$. De hecho, ya en 2005 el Parque Científico de la Usal se incorporó a través de su Fundación a esta Asociación. Poco a poco varias empresas y compañías se fueron sumando al proyecto ${ }^{42}$.

El 12 de diciembre de 2006 se colocó la simbólica primera piedra en presencia de representantes de todas las instituciones implicadas, pero la construcción de los edificios que debían acoger las instalaciones se ralentizó mucho debido, en gran parte, a la crisis económica que afectó al país en los años inmediatos.

Siguiendo el Plan Director se decidió ubicar el Parque Científico en dos parcelas unificadas del sector este (de 2,3 ha de superficie y 1,1 de edificabilidad), que como el resto de los terrenos donados se encontraba en un ámbito de expansión del municipio ordenado por el Plan Parcial Sector 14. Era una zona ya urbanizada con todos los servicios necesarios, en la que predominaba un trazado geométrico con parcelas regulares ocupadas por algunas viviendas y otros equipamientos, como un extenso campo de golf. Gracias a la aprobación de un nuevo Plan General de Ordenación Urbana de Villamayor fue posible incluir cambios en el aprovechamiento de la parcela ${ }^{43}$. Asimismo, dado su tamaño, la Fundación encargó al estudio de arquitectos dirigido por Emilio Sánchez Gil un proyecto de urbanización interior. Afectó a la parte del solar, sensiblemente llana, limitada por las calles Adaja al norte, Santibáñez del Río al sur y al oeste con una rotonda -la plaza de Gudino- y la avenida del Canto que recorría todo el Sector 14 de norte a sur, quedando al este un terreno inculto.

Desde el servicio técnico de la Universidad se habían previsto inicialmente cinco edificios exentos con la misma planta, colocados en paralelo, orientados perpendicularmente a la calle Adaja, con una separación entre ellos de quince metros y una amplia zona ajardinada en la parte sur. Por razones funcionales, posteriormente se decidió que solo tres de esos inmuebles fuesen iguales -el M1, M2 y M4- y los otros dos diferentes y más grandes, manteniendo entre ellos la misma separación.

${ }^{41}$ Remitimos a su web oficial, disponible en: https://www.apte.org/ [citado el 14 de marzo 2020].

${ }^{42}$ Corchado (2016), 19 y ss., hace un detallado seguimiento de las gestiones de la Universidad y señala las empresas que se van incorporando.

${ }^{43}$ En el Plan General, aprobado definitivamente el 24 de marzo de 2015 (BOCyL, 13 de abril de 2015), se incorporaron cambios de detalle, realizados con anterioridad, que afectaron a los parámetros de altura y al incremento de edificabilidad de esas parcelas. Moreno de Vega (2015). 


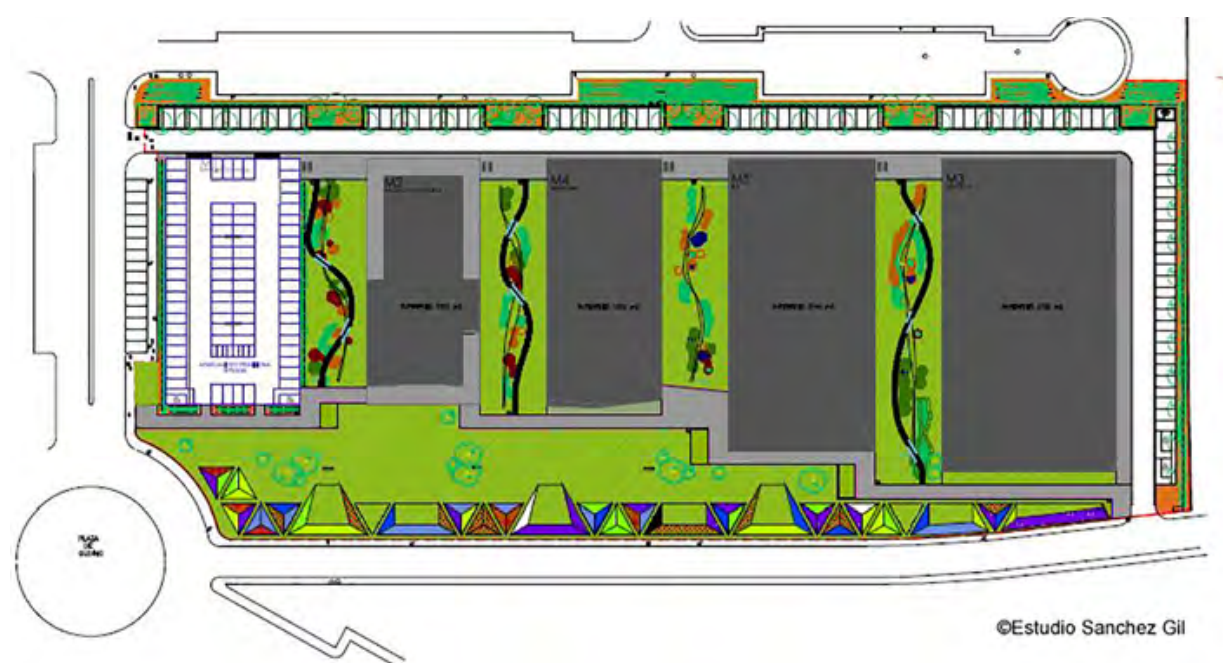

En el proyecto de urbanización redactado en $2009^{44}$, los arquitectos parten de la premisa de que el concepto de Parque Científico implica un área de trabajo con un alto contenido de investigación e innovación I+D, pero también un lugar de elevada calidad medioambiental, que en cierto modo lleva implícito el término "parque". Este hecho, unido a la privilegiada situación en las inmediaciones del Tormes, les lleva a minimizar las zonas pavimentadas -tanto peatonales como rodadas-, para destinar la mayor parte posible del espacio a zonas ajardinadas como elemento unificador del conjunto. Con este fin proponen una amplia pradera en forma de peine que envuelve por el sur, este y oeste los edificios, provista en el límite meridional de dunas vegetales de formas geométricas con distintos tipos de plantas aromáticas y arbustivas, para aislar de la calle. La pradera quedaría también salpicada con arbustos y árboles de ribera, como fresnos y olmos, que sin quitar la vista a los edificios produjesen algunos espacios de sombra, volumen y color.

Aunque la vegetación autóctona pretenda ser el elemento dominante en el espacio del Parque Científico, dado que la mayor parte del personal usaría el automóvil para sus desplazamientos, se consideró conveniente construir un aparcamiento de superficie provisional dentro de la parcela reservada al Módulo M1, y distribuir otras plazas tanto en el límite oriental, con una hilera de árboles de sombra que actuase de separación entre el Parque y el exterior, como en el lado septentrional, donde se proyectó un

${ }^{44}$ Emilio Sánchez Gil, Fernando Sánchez Cuadrado, Emilio Sánchez Cuadrado, Memoria descriptiva del proyecto de urbanización del Parque Científico. Abril de 2009. Facilitada por los autores. 
aparcamiento en batería discontinuo, intercalado con parterres con árboles y setos, para reducir el impacto visual y cerrar el espacio con respecto a la zona residencial próxima.

Dentro del recinto hay un camino peatonal principal, de oeste a este, solado con pequeños adoquines en basalto negro, que va recorriendo los accesos principales situados en la parte sur. Su trazado se quiebra en tramos aprovechando la disposición de los edificios. Otro camino de servicio más estrecho discurre por el norte de la parcela, adosado a la vía rodada que en forma de L se extiende también por el lado este. De momento solo se han trazado a los lados del M2 otros senderos curvilíneos proyectados en las praderas, entrelazados con pequeños arroyos que discurrirían entre los edificios.

Parte de la zona verde está todavía sin completar al no haberse concluido el M4 promovido por la Fundación Nido de Mariano Rodríguez en la parcela que la Universidad le cedió en 2009. Esta Fundación pretendía fomentar la innovación prioritariamente en el sector agroalimentario y de la construcción. El edificio se inició en 2008 con un proyecto que costeó la Fundación Parque Científico ${ }^{45}$, pero quedó paralizado en 2010 por quiebra del grupo, con parte de su estructura levantada. Posteriormente la Universidad ha sacado a concurso público en varias ocasiones la cesión del suelo, pero de momento no ha encontrado ninguna entidad dispuesta a finalizar la construcción y explotarla durante unos años ${ }^{46}$.

Mejor suerte tuvieron otros edificios, aunque el retraso en comenzarlos conllevó cambios en el destino que inicialmente se había previsto para ellos. Así, en verano de 2008 el equipo de gobierno decidió no trasladar a Villamayor los servicios científicos de la Universidad y destinar todos los espacios a empresas tecnológicas de investigación, desarrollo e innovación en régimen de alquiler, de modo que el Módulo de Ciencias de la Tierra (M2) perdió esa condición ${ }^{47}$.

El M2 fue proyectado por Emilio Sánchez Gil y sus hijos Fernando y Emilio Sánchez Cuadrado en 2006, aunque su construcción se prolongó hasta $2010^{48}$. Conforma un bloque cúbico de tres plantas, ligeramente rehun-

${ }^{45}$ Fundación Parque Científico. Memoria de Actividades. Año 2012, 4.

${ }^{46} \mathrm{Ni}$ la Universidad ni la Fundación del Parque estaban en condiciones de afrontar una inversión de ese calado y las empresas que parecían dispuestas en 2005 acabaron desistiendo. De nuevo salió a licitación pública en 2018 sin éxito. Tribuna de Salamanca, 5/6/2015 y 4/12/2018. La Vanguardia, 4/12/18.

${ }^{47}$ Corchado (2016), 25-26.

${ }^{48}$ Sánchez Gil, "Modulo Tecnológico M2, Universidad De Salamanca", 30 enero 2014 Plataforma Arquitectura [citado el 6 de marzo 2020]: disponible en https://www.plataforma- 


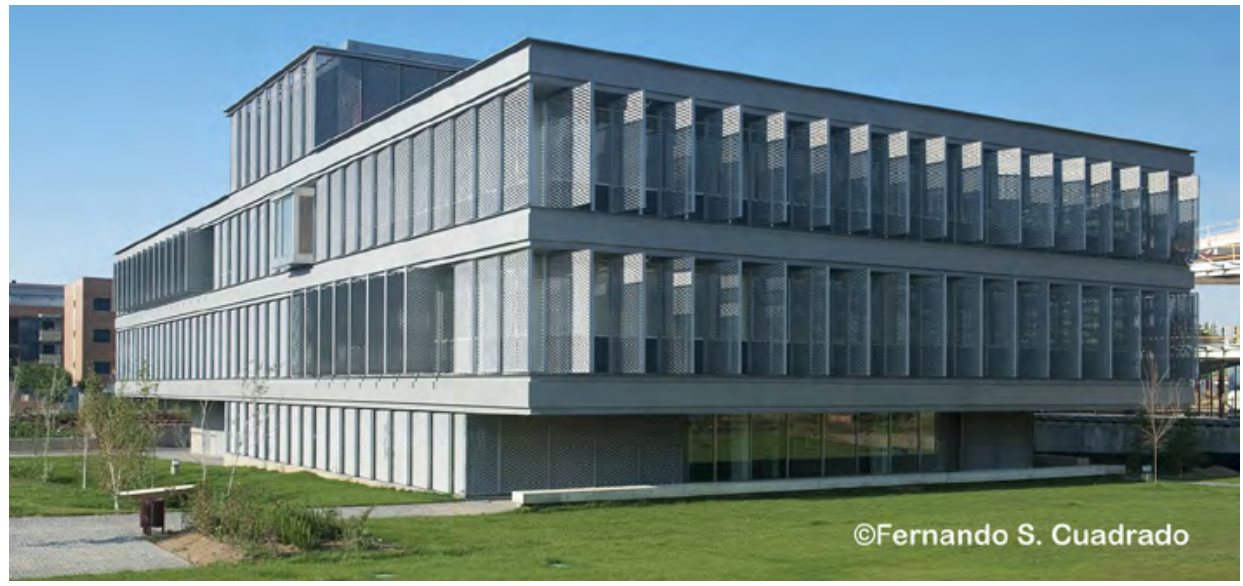

dido en el terreno para reducir el impacto edificatorio. La fachada inferior está remetida en la mayor parte del perímetro para dejar una zona porticada mientras los niveles superiores se cierran con una doble piel que define el carácter arquitectónico. La exterior está formada por paneles móviles motorizados de chapa de acero estirada que permiten controlar la luminosidad y el soleamiento, mientras que en la interior se emplea pizarra y vidrio con una galería metálica entre ambas para renovación de aire, de ancho variable en función de la orientación. Esta piel interior genera en algunos puntos del flanco oriental y occidental espacios intersticiales singulares, a modo de umbríos patios con vegetación, que iluminan los vestíbulos de acceso a las áreas de trabajo y escaleras.

El espacio interior se articula a partir de un gran hall circular que atraviesa las tres plantas culminado por un lucernario cónico invertido de madera que permite la entrada de luz cálida y tamizada. A uno y otro lado se distribuyen las distintas áreas de trabajo concebidas -al haberse modificado su uso- como espacios diáfanos, con perímetro acristalado, que se iluminan y organizan mediante pequeños patios ajardinados interiores. En la planta baja se contempla una gran área de descanso de uso común.

La Fundación Parque Científico obtuvo en 2009 una subvención de 3.000.000 de euros del Ministerio de Ciencia e Innovación para finalizar esta obra, que superó los cuatro millones y medio ${ }^{49}$. Con este edificio, inaugurado

arquitectura.cl/cl/02-331850/modulo-tecnologico-m2-universidad-de-salamanca-sanchezgil-arquitectos.

${ }^{49}$ DiCYT. 4/11/2009 [citado el 6 de marzo 2020]: disponible en http://www.dicyt.com/ viewNews.php?newsId=15434. 

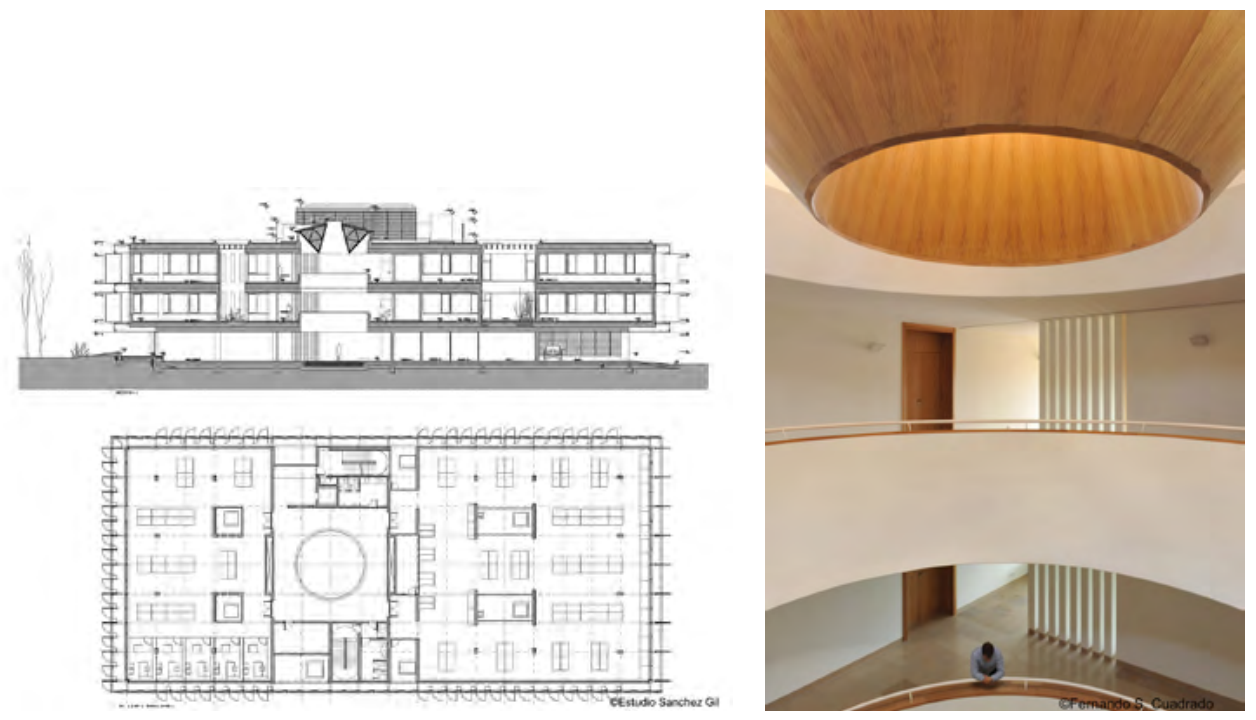

el 11 de noviembre de 2010 con la presencia en el acto de la ministra, Cristina Garmendia ${ }^{50}$, empezaba a hacerse realidad el Parque Científico. Una de las primeras empresas que se instaló allí fue INDRA y en la actualidad ocupa la mayor parte de su espacio. La urbanización, ajardinamiento y aparcamiento de la parcela donde estaba ubicado también se encontraba muy avanzada ${ }^{51}$.

Parecía que el Módulo M3 podría estar también operativo en poco tiempo. El inicio de su historia podría remontarse a la firma, en febrero de 2006, de un convenio entre la Universidad de Salamanca y la Consejería de Economía y Empleo de la Junta de Castilla y León, por el que esta última se comprometía a "impulsar la construcción y financiación del edificio" a través de la empresa pública Gesturcal (después ADE Parques) ${ }^{52}$, que asumiría, asimismo, la dirección facultativa de las obras y el coste del proyecto arquitectónico y de ejecución, diseñados de acuerdo con las características y el programa de necesidades definidos por la Usal. La Consejería se comprometía además a "participar en la gestión del edificio y en la selección de las empresas destinadas a ocuparlo" 53 .

${ }^{50}$ La Gaceta Regional, 13/11/2010.

${ }^{51}$ Fundación Parque Científico. Memoria de Actividades 2009-2010.

${ }^{52}$ Integrada ahora en el Instituto para la Competitividad Empresarial (ICE)

${ }^{53}$ Convenio de colaboración para la promoción, ejecución y gestión de un edificio de espacios de alquiler para empresas en el "Parque Científico" de la Universidad de Salamanca. Disponible en: http://campus.usal.es/gabinete/comunicacion/Convenio_Gesturcal_2006.pdf [citado el 6 de marzo 2020], 

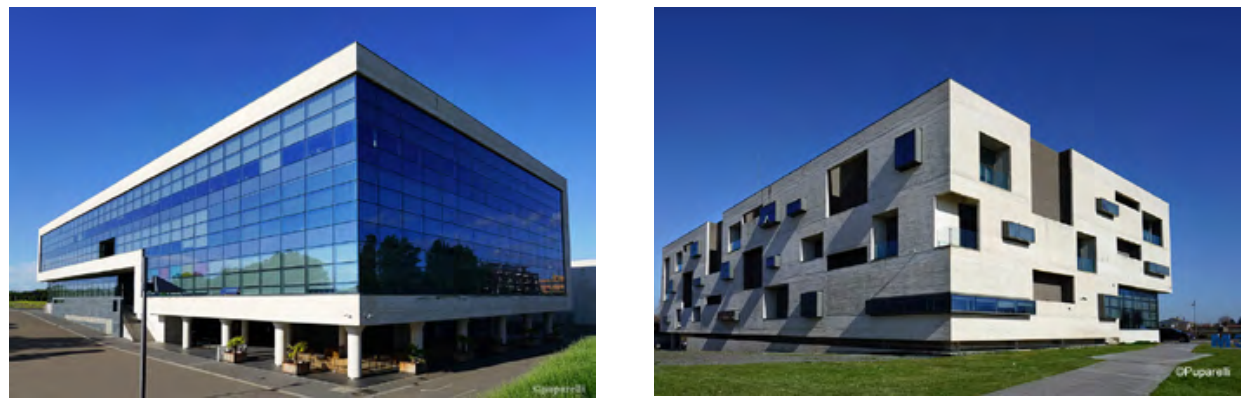

A pesar del convenio, la construcción no se inició de inmediato y en 2009 la Universidad renegoció con la Junta la reforma del proyecto al no poder asumir su elevado presupuesto ${ }^{54}$. Finalmente obtuvo un préstamo del Ministerio de Ciencia e Innovación que, como otros recibidos, a la larga supusieron un problema para la Fundación Parque Científico al tener que devolverlos antes de empezar a obtener beneficios de los alquileres ${ }^{55}$. No obstante, le permitió concluir el inmueble que entró en funcionamiento meses antes de su inauguración oficial en julio de 2012. Su coste superó los once millones de euros ${ }^{56}$.

El autor del M3 fue el arquitecto de Valladolid José Ramón Sola Alonso. Se configura como un gran bloque cúbico que incluye sótano y dos plantas sobre el bajo, de manera que la altura viene a ser similar a la del M2. Su forma exterior está definida por dos tipos de fachadas en función de la orientación. La occidental y meridional presentan un aspecto opaco, con muros de hormigón animados por huecos geométricos de distintos tamaños, que asimétricamente se hunden o se proyectan al exterior a modo de cubos ingrávidos. En las otras dos, el hormigón sirve de marco a un cierre totalmente acristalado.

Arquitectónicamente se buscó la mayor versatilidad, por lo que en el interior se proyectaron espacios diáfanos que se pudieran dividir en razón de la demanda. Las comunicaciones verticales están alojadas en un patio longitudinal que perfora el volumen proporcionándole luz. Se convirtió también en un enclave abierto de exposiciones, al acoger más de veinte piezas de la serie "Geometrías" de Patxi Gutiérrez ${ }^{57}$.

${ }^{54}$ Corchado (2016), 19, 23 y 33. DiCYT, 4/11/2009 [citado el 6 de marzo de 2020] disponible en http://www.dicyt.com/viewNews.php?newsId=15434.

${ }^{55}$ Corchado (2016), 28-30.

${ }^{56}$ DiCYT, 23/07/2012 [citado el 6 de marzo 2020]: disponible en https://www.dicyt.com/ noticias/el-edificio-m3-del-parque-cientifico-de-la-usal-una-apuesta-por-la-investigacion-yla-innovacion

${ }^{57}$ Inauguración del edificio M3. Dosier. Fundación Parque Científico. 


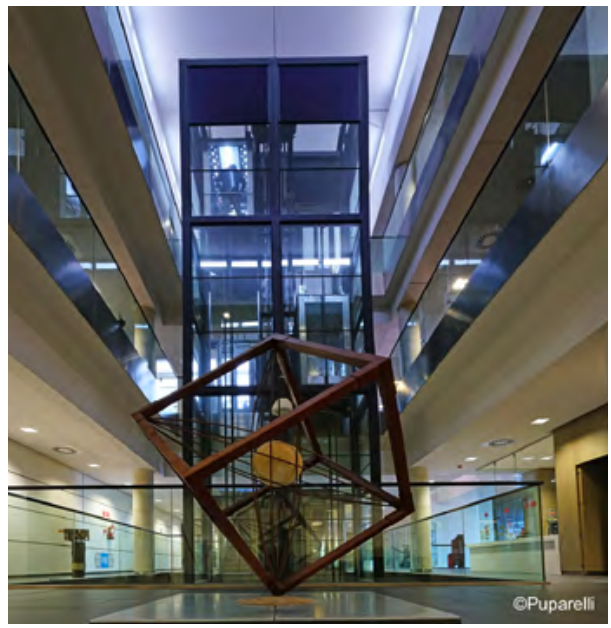

En 2016, tras la reversión a la Fundación Parque Científico de la gestión y explotación de todo el edificio $^{58}$, se encargó a la empresa Giveme3, una serie de mejoras en diferentes espacios, que son parte de la imagen actual. Así, llama la atención la decoración y mobiliario de un área de esparcimiento, convertible en aulario de congresos o coffee time; o la pequeña sala de formación protagonizada por el inventor Hugo Gernsback.

Al ser el edificio de mayor tamaño del Parque Científico, además de las oficinas, se incluyeron entre sus dotaciones un restaurante y una guardería, cuyos servicios están abiertos no solo a los trabajadores del mismo sino también a toda la población. En la actualidad el M3 lo ocupan principalmente empresas del sector TIC y acoge el Centro de Procesamiento de Datos del Parque y la gerencia.

A comienzos de 2012, una zona del M3 fue alquilada y habilitada con varios laboratorios para acoger el personal y el equipamiento del Centro de Láseres Pulsados Ultracortos (CLPU), instalado hasta el momento en la Facultad de Físicas, hasta que estuviese concluido el edificio destinado a albergarlo, el M559.

El CLPU constituye una infraestructura científico-tecnológica muy vanguardista. Nació como fruto de un Consorcio firmado el 14 de diciembre de 2007 entre el entonces Ministerio de Educación y Ciencia, la Junta de Castilla

${ }^{58}$ Memoria del curso académico 2013-2014. Studii Salamantinii [citado el 6 de marzo 2020]: disponible en http://campus.usal.es/ memoria/1314/07_investiga/7_1_vic_investiga.html

${ }^{59}$ Memoria de Actividades CLPU, 2012. 
y León y la Universidad de Salamanca. Como parte de sus fines, el CLPU desarrollaría "experimentación e investigación científica y tecnológica en todos los aspectos relativos a láseres pulsados ultraintensos con una plantilla de científicos y tecnólogos propios", pero sería a la vez una instalación "abierta al uso de la comunidad científica y tecnológica nacional", con clara apertura a la colaboración internacional y a todas las iniciativas en este campo ${ }^{60}$.

Por encargo del Consorcio, ya en marzo de 2009 los arquitectos Agustín Ferreira y Luis Ferreira Villar presentaron una propuesta arquitectónica y el proyecto básico ${ }^{61}$, pero el edificio no se empezó a construir hasta comienzos de 2011. A la hora de diseñar el inmueble se tuvieron que cumplir una serie de características técnicas específicas, dada la singularidad del equipamiento que iba a albergar, en especial el sistema de laser VEGA, destinado a convertirse en uno de los diez láseres más potentes del mundo.

Está pensado en tres niveles. El semisótano es la zona clave y está compuesto por dos áreas diferenciadas contiguas en disposición longitudinal. Por un lado, una sala de unos $60 \mathrm{~m} \times 10 \mathrm{~m} \times 6 \mathrm{~m}$ de alto construida a modo de bunker -con dos losas de hormigón armado mediadas por una cama de arena en el suelo y dos muros del mismo material-, en la que está ubicado el láser de Petavio con estricto control de temperatura, radioactividad ambiental, humedad y estabilidad geológica, para su correcto funcionamiento. Y por

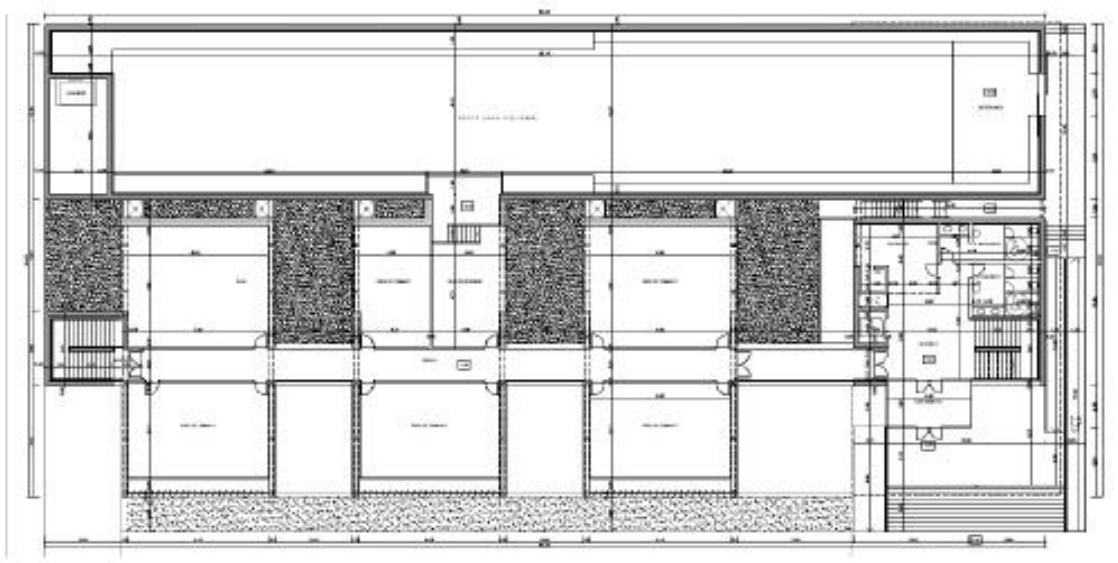

eVicente/Nuñez

60 “Estatutos del Consorcio para el diseño, construcción, equipamiento y explotación del centro de láseres pulsados ultracortos ultraintensos". BOE, 17/10/2008, 41641.

${ }^{61}$ Agustín Ferreira, Luis Ferreira Villar: Proyecto básico y estudio de necesidades para la ejecución de un contrato para la sede del Laser Petavatio. Memoria. Marzo 2009. 


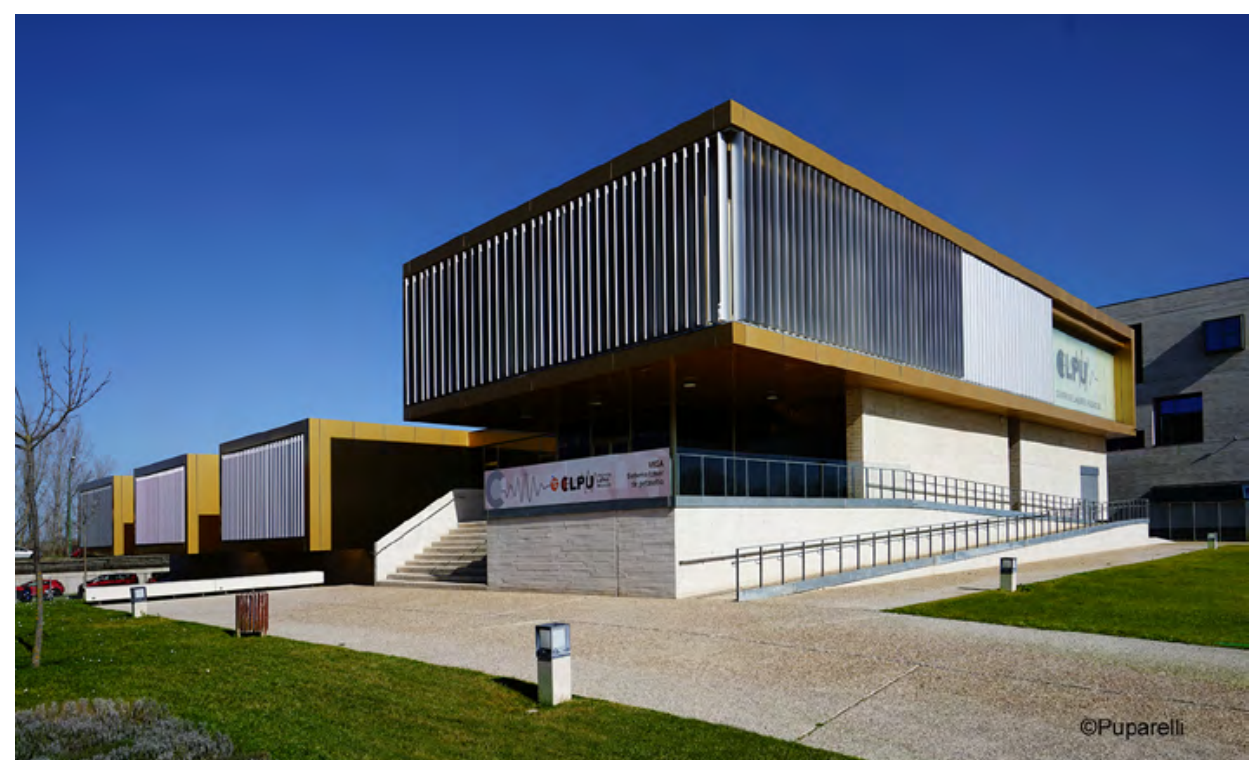

otro, la zona destinada a la experimentación, con características similares a la anterior, que aloja cuatro laboratorios diseñados de acuerdo con un criterio de máxima versatilidad mediante tabiques móviles. En el centro está la sala de control y en el extremo sur el vestíbulo que comunica con el de la planta baja situada sobre esta área, con entrada desde el exterior a través de una rampa y amplias escaleras. Una pasarela acristalada sirve de acceso desde la zona de recepción a los distintos espacios de este nivel, que incluye cuatro salas de trabajo para grupos reducidos y un aula con capacidad para cincuenta personas, además de despachos de investigadores y técnicos y una zona de descanso y control. Se establece así una secuencia entre los espacios exteriores y los interiores, conformados por bloques cúbicos. Sobre el vestíbulo de entrada, y con la misma configuración, se levanta otra planta donde se ubican los despachos de dirección, gerencia y sala de juntas.

El edificio queda así constituido por tres volúmenes espacial y funcionalmente diferenciados pero con comunicación fluida entre las distintas áreas. Cabe destacar los grandes voladizos de más de siete metros de las áreas de trabajo de la planta baja y primera sustentados mediante cerchas metálicas, con fachadas revestidas por paneles de aluminio de gran resistencia a la corrosión y sus grandes vanos acristalados con celosías orientables de aluminio que mejoran el confort interior de las diferentes estancias.

La ejecución y dirección de las obras, a cargo de la empresa Ferrovial Agromán, fue adjudicada por concurso público a los conocidos arquitec- 
tos Pablo Núñez y Juan Vicente Herrera. Se financió en un 70\% por fondos FEDER y el resto por el Consorcio ${ }^{62}$.

La construcción de este edificio, que cumple las normas del Consejo de Seguridad Nuclear y se ajusta a otros criterios de sostenibilidad ambiental, supuso todo un reto tecnológico por la complejidad que conllevaba. Las soluciones innovadoras que se aplicaron en él, despertaron el interés del sector. Así, la Universidad de Santiago que estaba acometiendo la instalación de un sistema láser de 10 TW, desplazó una delegación para conocer las medidas técnicas implementadas en él. También fue objeto de estudio por parte de los arquitectos y técnicos de la insfraestructura ELI Hungría, de mayor envergadura $^{63}$. El traslado del CLPU a la nueva sede se realizó en octubre de 2013, aunque desde un año antes se sucedieron en la prensa las noticias sobre su inminente conclusión.

Como señalábamos al principio, estos son solo algunos de los edificios promovidos por la Universidad de Salamanca en el siglo XXI. Sus sucesivos gobiernos han apostado por mantener la tradicional vinculación con la ciudad, evitando las acusadas segregaciones que se aprecian en otras universidades españolas. Prueba clara de ello es la decisión de no trasladar a Villamayor, frente a lo proyectado en el plan director de ese campus, centros docentes ni tampoco servicios científicos, soslayando así los problemas de desplazamiento que esta localización habría supuesto para los estudiantes. La ubicación de los Institutos de Neurociencias y de Biología Funcional en parcelas próximas al campus Miguel de Unamuno puede considerarse la punta de lanza para la nueva expansión hacia la zona de la Platina, un área urbanizada inmediata al cementerio al oeste de Salamanca, todavía con escasa ocupación, donde parece ya decidida la construcción de un gran "campus agroambiental" con la Facultad de Ciencias Agrarias como punto de partida. En Villamayor, sin embargo, ha empezado a funcionar el Parque Científico, con unos edificios e instalaciones modernas acordes a las necesidades funcionales de las empresas allí instaladas, más alejado de otros recintos universitarios pero al mismo tiempo con una comunicación fluida con Salamanca gracias a la planificación urbanística desarrollada en los últimos años por dicho municipio.

\footnotetext{
${ }^{62}$ El presupuesto inicial fue de 3,8 millones de euros. Memoria de Actividades CLPU 2010, 32.

${ }^{63}$ Dirección General de Fondos Comunitarios. Dosier sobre CLPU [citado el 25 de marzo 2020]: disponible en https://www.dgfc.sepg.hacienda.gob.es/sitios/dgfc/es-ES/ipr/fcp0713/c/ bp/ac/ac2013/Documents/BPAC2013PLURIS_2.pdf
} 
Bibliografía

Campos Calvo-Sotelo, Pablo, "Plan Director del nuevo recinto de la Universidad de Salamanca en Villamayor", Urban. Revista de Urbanística y Ordenación del Territorio, 11 (2006), 120-126.

Campos Calvo-Sotelo, Pablo. El paradigma del "Campus Didáctico": revisión conceptual y proyección en los espacios físicos de la Universidad. Salamanca: Ediciones de la Universidad de Salamanca, 2017.

CañIzal SARdón, SARa. La Universidad de Salamanca de la posguerra a la actualidad. Patrimonio arquitectónico y trascendencia urbana. Tesis doctoral: Universidad de Salamanca, 2009.

Carta, Silvio. "Vicente/Núñez, Neuroscience Institute in Castilla y León. Portuguese Agricultural Research Center-Ciale", C3, 311 (2010), 1842003.

Corchado, Juan Manuel. Diez años del Parque Científico de la Universidad de Salamanca. Salamanca: Ediciones Universidad Salamanca, 2016.

EDWARD, BRIAN. University Architecture. London: Spon Press, 2000.

Ferreira, Agustín; Ferreira Villar, Luis. Proyecto básico y estudio de necesidades para la ejecución de un contrato para la sede del Laser Petavatio. Memoria. Marzo 2009.

Fundación Parque Científico de la Universidad de Salamanca Memoria de actividades 2007-2008.

Memoria de actividades 2009-2010.

Memoria de Actividades. Año 2012.

MATA Y Asociados, "Instituto de Biología Funcional y Genómica". Plataforma Arquitectura (28 nov 2012 [citado el 8 de mayo 2020]: disponible en https://www.plataformaarquitectura.cl/cl/02-211187/instituto-debiologia-funcional-y-genomica-mata-y-asociados

Moreno De Vega, Miguel Ángel, Estudio de detalle para la modificación de las parcelas CS.EQ.01 del Parque Científico de la Universidad de Salamanca. Septiembre 2015. (20/05/2016 [citado el 14 de marzo 2020]. Junta de Castilla y León: disponible en http://www.jcyl.es/plaupdf//37/37354/292962/DOCUMENTO.pdf

Muñoz Torres, ElisA. Memoria de Actividades del Curso Académico 20052006. Universidad de Salamanca, Secretaría General, 2006

NEuman, David J. Building type basis for college and University Facilities. Hoboken NJ: John Wiley, 2013.

Núñez Paz, Pablo y Vicente García, Juan. "Análisis. Instituto de Neurociencias de Castilla y León”, Pasajes. Arquitectura y crítica, 96 (2008), 30-37. 
Núñez Paz, Pablo y Vicente García, Juan. “Centro Hispano-Luso de Investigaciones Agrarias (C.I.A.L.E.)”, Pasajes. Arquitectura y crítica, 105 (2009), 14-15.

Núñez Paz, Pablo y Vicente García, Juan. "Instituto de Neurociencias de Castilla y León". Plataforma Arquitectura. (02 abr 2012 [citado el 6 de abril 2020]: disponible en https://www.plataformaarquitectura.cl/ cl/02-149168/instituto-de-neurociencias-de-castilla-y-leon-canvasarquitectos

Paliza, María Teresa y Senabre, DAvid. "Arquitecturas y espacios universitarios, siglos XIX y XX". Historia de la Universidad de Salamanca. II. Estructuras y flujos. Luis Enrique Rodríguez-San Pedro Bezares (coord.), Salamanca: Ediciones de la Universidad de Salamanca, 2002, pp. 487-521.

SÁNCHEZ GiL, EMiLIo. "Modulo Tecnológico M2, Universidad De Salamanca" Plataforma Arquitectura (30 enero 2014 [citado el 6 de marzo 2020], disponible en https://www.plataformaarquitectura.cl/cl/02-331850/modulo-tecnologico-m2-universidad-de-salamanca-sanchez-gil-arquitectos SÁNCHEZ Gil, Emilio. "Instituto de Investigación del Cáncer. Salamanca". On Diseño, 227 (2001): 188-199.

Sánchez Gil, Emilio; SÁnchez Cuadrado, Fernando; Sánchez Cuadrado, Emilio. Memoria descriptiva del proyecto de urbanización del Parque Científico. Abril de 2009.

Vicente, JuAn y Núñez, Pablo. Memoria del Instituto de Neurociencias de Castilla y León, s. f.

Vicente/NÚÑEZ ARQuitectos. "CIALE. Centro hispano luso de Salamanca”, en Síntesis Arquitectura. Castilla y León, Manuel Rúa García (ed.), Madrid, 2011, pp. 14-35. 